\title{
Will Extratropical Storms Intensify in a Warmer Climate?
}

\author{
LENNART BENGTSSON \\ National Centre for Earth Observation, University of Reading, Whiteknights, Reading, United Kingdom, \\ and Max Planck Institute for Meteorology, Hamburg, Germany \\ KEVIN I. HODGES \\ National Centre for Earth Observation, University of Reading, Whiteknights, Reading, United Kingdom \\ NOEL KEENLYSIDE \\ Leibniz Institute of Marine Sciences, IFM-GEOMAR, West Shore Campus, Kiel, Germany
}

(Manuscript received 12 June 2008, in final form 22 October 2008)

\begin{abstract}
Extratropical cyclones and how they may change in a warmer climate have been investigated in detail with a high-resolution version of the ECHAM5 global climate model. A spectral resolution of T213 $(63 \mathrm{~km})$ is used for two 32-yr periods at the end of the twentieth and twenty-first centuries and integrated for the Intergovernmental Panel on Climate Change (IPCC) A1B scenario. Extremes of pressure, vorticity, wind, and precipitation associated with the cyclones are investigated and compared with a lower-resolution simulation. Comparison with observations of extreme wind speeds indicates that the model reproduces realistic values.

This study also investigates the ability of the model to simulate extratropical cyclones by computing composites of intense storms and contrasting them with the same composites from the 40-yr ECMWF ReAnalysis (ERA-40). Composites of the time evolution of intense cyclones are reproduced with great fidelity; in particular the evolution of central surface pressure is almost exactly replicated, but vorticity, maximum wind speed, and precipitation are higher in the model. Spatial composites also show that the distributions of pressure, winds, and precipitation at different stages of the cyclone life cycle compare well with those from ERA-40, as does the vertical structure.

For the twenty-first century, changes in the distribution of storms are very similar to those of previous study. There is a small reduction in the number of cyclones but no significant changes in the extremes of wind and vorticity in both hemispheres. There are larger regional changes in agreement with previous studies.

The largest changes are in the total precipitation, where a significant increase is seen. Cumulative precipitation along the tracks of the cyclones increases by some $11 \%$ per track, or about twice the increase in global precipitation, while the extreme precipitation is close to the globally averaged increase in column water vapor (some $27 \%$ ). Regionally, changes in extreme precipitation are even higher because of changes in the storm tracks.
\end{abstract}

\section{Introduction}

Experiments with high-resolution models indicate that tropical cyclones are likely to intensify in a warmer climate (Meehl et al. 2007a), most importantly in terms of their winds and precipitation, though the number of storms will likely be fewer (Oouchi et al. 2006;

Corresponding author address: K. I. Hodges, National Centre for Earth Observation, University of Reading, Whiteknights, P.O. Box 238, Reading RG6 6AL, United Kingdom.

E-mail: kih@mail.nerc-essc.ac.uk
Bengtsson et al. 2007). As suggested in Bengtsson et al. (2007) this dichotomy is likely related to the fact that water vapor increases more rapidly than precipitation in a warming climate. This then implies a weakening in the large-scale vertical mass flux (Held and Soden 2006), thus providing less favorable conditions for the onset of tropical cyclones. However, when favorable conditions do occur they make use of the increased humidity. This may also happen for other convectively driven systems (Allan and Soden 2007).

Changes in extremes of extratropical cyclones with climate warming are less clear (Meehl et al. 2007a). 
Extratropical cyclones form and grow via baroclinic instability, getting their main kinetic energy from the conversion of available potential energy, though some contribution may also come from latent heat release. Available potential energy is proportional to the variance of temperature in the troposphere. This is why extratropical cyclones are more intense during winter when the temperature variance is highest. Climate models integrated with higher concentrations of greenhouse gases generally show a reduced temperature gradient in the lower troposphere of the Northern Hemisphere $(\mathrm{NH})$ at least during winter because of a stronger Arctic warming. This implies that the available potential energy will decrease. With this reasoning extratropical cyclones might be more intense in a colder climate. There is support for this from both observational reconstructions (Björck and Clemmensen 2004) and recent model simulations of the seventeenth century replicating the climate conditions during the so-called Maunder minimum (Raible et al. 2007) at a time when the European winter climate was generally much colder than during the twentieth century.

It is important to be clear on what we mean by the intensity of extratropical storms. In many studies this is taken to be the depth of the pressure center or the magnitude of the vorticity. However, pressure may be misleading because of changes at the larger scale while the parameters that matter to the public are winds and precipitation; these are the focus of this work.

To determine any observational changes in extremes of winds and precipitation, associated with cyclones, is difficult since observational records only exist for restricted regions. For winds this is mainly confined to the northeast Atlantic and the North Sea (WASA Group 1998, and references therein). A detailed analysis of these observations (Weisse et al. 2005) does not show any long-term trends but indicates considerable variability at a wide range of time scales. Even for observational reconstructions that go back to the latter part of the nineteenth century it is impossible to identify any persistent trend, but instead periods when intense winds were more common than in other periods are seen (see Trenberth et al. 2007, their Fig. 3.41). There have been only limited regional studies of changes in extreme precipitation. For example, Karl and Knight (1998) investigated the contribution of the upper 10th percentile of daily precipitation and noted a positive trend during the twentieth century for an area averaged over the central part of the United States. Other studies that report observed increases in precipitation for several regions are summarized in the Climate Change Science Program (CCSP) report (Karl et al. 2008, chapter 2). Model studies by Semenov and Bengtsson (2002) show similar increasing trends.
It has been suggested that higher sea surface temperatures (SST) at mid- and high latitudes will imply an intensification of extratropical cyclones, but this is hardly likely, at least in winter. The reason is that higher SST will act as a sink on available potential energy, because of a more rapid warming of the cold air than the warmer air, which will consequently result in a reduction of the available potential energy. Rather it is more likely that it is the strengthening of the SST gradients that may favor extratropical cyclones (Inatsu et al. 2003). As discussed by Bengtsson et al. (2006), such changes are expected as a consequence of a future warming in the Southern Hemisphere (SH) ocean and also over limited areas of the North Atlantic. In the North Atlantic this appears to be related to the weakening of the thermohaline circulation. This leads to the generation of an area south of Greenland with a regionally reduced SST warming and in some coupled models a minor cooling. The enhanced SST gradient south of the cooler region will increase the baroclinicity in the lower troposphere, creating, in principle, more favorable conditions for extratropical cyclones.

An additional factor is tropical cyclones and mesocyclones. Tropical cyclones can be transformed into extratropical storms as they migrate poleward. As tropical storms generally are intensified in a warmer climate (Oouchi et al. 2006; Bengtsson et al. 2007), this may contribute to an enhancement of storms even at higher latitudes but mainly in late summer and autumn. Mesocyclones such as polar lows are also found in the extratropics. Polar lows are found at high latitudes during the winter season and develop over open water in situations of cold Arctic air masses. We might expect polar lows to be less common in a warmer climate, but this may be influenced by the reduction of Arctic sea ice and they could be more common over the Arctic Ocean. Mesocyclones, as well the convective storms that occur during the warm period months, may well be more likely to be affected by changes in latent heat release than synoptic-scale systems.

There have been many studies of the impacts of a warmer climate on extratropical cyclones (Ulbrich et al. 2009). The most recent studies have been based on the climate scenarios (Nakicenovic and Swart 2000) used for the Intergovernmental Panel on Climate Change (IPCC) Fourth Assessment Report (AR4; Solomon et al. 2007). Lambert and Fyfe (2006) assessed cyclones in a range of climate model data archived for AR4 in the Coupled Model Intercomparison Project 3 (CMIP3) archive (Meehl et al. 2007b) for a number of the scenarios. Because of CMIP3 archiving limitations, their study was limited to identifying surface pressure minima in daily averaged data. Extremes were taken to be lower than 
$970 \mathrm{hPa}(960 \mathrm{hPa})$ for the $\mathrm{NH}(\mathrm{SH})$. They found that the models simulated a reduction in the total number of events and an increase in the number of intense events. With their methods they did not find any changes in the location of the storm tracks and did not present any results for winds or precipitation. Leckebusch and Ulbrich (2004) investigated the relationship between cyclones and extreme windstorms over Europe under climate change using data from the third climate configuration of the Met Office Unified Model (HadCM3) with a horizontal latitude-longitude resolution of $2.5^{\circ} \times 3.75^{\circ}$ and the IPCC A2 and B2 scenarios (Nakicenovic and Swart 2000). They compared the period 2070-99 with the control period 1960-89. Extreme wind events were defined as values above the 95th percentile for daily maximum wind speeds associated with the nearest cyclone. For both scenarios, they found an enhancement of cyclone activity over the areas around the British Isles and the North Sea and a weakening in the northern part of the Norwegian Sea.

In the study of Bengtsson et al. (2006) an ensemble of three 30-yr integrations of the Max Planck Institute (MPI) coupled atmosphere-ocean model (OM; ECHAM $\mathrm{OM}$ ), integrated at $\mathrm{T} 63$ spectral resolution in the atmosphere, was used to compare storm tracks for the A1B scenario for the period 2070-99 with the control period 1960-89. Their evaluation, based on vorticity, was for the whole globe. Their results showed a poleward shift of the extratropical storm tracks in both hemispheres in agreement with Yin (2005) and Fischer-Bruns et al. (2005) and other Lagrangian studies, for example, Teng et al. (2008). There was no indication of any intensification, except regional changes associated with the poleward shift. These results are similar to those obtained by Löptien et al. (2008) using the same data but a different Lagrangian analysis system. In this respect these results are just the opposite of that of Lambert and Fyfe (2006).

Evidence from such studies are summarized in the latest IPCC report (Meehl et al. 2007a, p. 751) as the following statement: "Model projections show fewer mid-latitude storms averaged over each hemisphere, associated with the poleward shift of the storm tracks that is particularly notable in the $\mathrm{SH}$, with lower central pressures for these poleward-shifting storms. The increased wind speeds result in more extreme wave heights in those regions." Though a bit imprecise, this statement suggests that midlatitude cyclones will become more intense in a warmer climate.

There are several reasons why we believe it is important to reassess the way extratropical cyclones may be affected by a warmer climate. First, as shown by the WASA Group (1998), the wind speed is not strongly correlated with the surface pressure of a transient cy- clone. Second, the most recent global studies of extratropical cyclones have been undertaken using datasets of coarse horizontal resolution, such as the AR4 models. Third, the datasets have suffered from a coarse time resolution making it virtually impossible to identify rapid changes in the wind speed.

Here we revisit the previous study by Bengtsson et al. (2006) for extratropical cyclones, but use the ECHAM5 atmospheric model at the higher spectral resolution of T213. The integrations cover the periods $1959-90$ and 2069-2100 using the IPCC scenario A1B (Nakicenovic and Swart 2000). For a detailed description see Bengtsson et al. (2007). The increased resolution makes it possible to obtain a better determination of the characteristics of intense extratropical storms including associated extreme winds and precipitation. We concentrate this assessment on the winter [December-February (DJF)] season of the $\mathrm{NH}$ but will provide some general comments on the other seasons and the SH.

The following scientific objectives will be addressed in this study:

1) What is the impact of model resolution on extratropical cyclones?

2) What is the typical structure and life cycle of extratropical cyclones at T213 resolution in terms of characteristics such as the depth, vorticity, wind speed, and precipitation? How realistically do these results agree with those from reanalyses?

3) How do intense extratropical cyclones respond to climate warming and what regional and seasonal differences are found?

The paper continues in section 2 with a description of the experiments, data, and analysis methodologies. In section 3 a comparison between storm properties from the T63 and T213 integrations are presented. In section 4 , the composite structure and evolution of the most extreme extratropical cyclones are compared with those from reanalyses. Section 5 describes the change in the extratropical storms at the end of the twenty-first century and contrast is made with gridpoint statistics of extremes. In section 6 we summarize the results of the study, and in section 7 some final comments are made.

\section{The experiment, data, and analysis methodologies}

The experimental setup for this study is essentially the same as that used for the study of tropical cyclones by Bengtsson et al. (2007). The MPI, ECHAM5 atmosphere model (Roeckner et al. 2003) is integrated at T213 spectral resolution $(63 \mathrm{~km})$ with 31 levels in the vertical using the "time slice" method. This is comparable to the horizontal resolution of several limited-area 
models. This is used to simulate the climate of two 32-yr periods that are representative of the end of the twentieth (1959-90) and twenty-first (2069-2100) centuries, using the IPCC scenario A1B. These will hereafter be referred to as $20 \mathrm{C}$ and $21 \mathrm{C}$, respectively. To provide the boundary forcing for these integrations, SST and sea ice fraction data from one of the three T63 $(208 \mathrm{~km})$ ECHAM5OM coupled model integrations for the A1B scenario produced for the IPCC AR4 (Roeckner et al. 2006) are used. These are the same integrations used for the Bengtsson et al. (2006) study. The SST and sea ice fraction data are interpolated from the original T63 resolution to T213. The original T213 integrations of the ones used by Bengtsson et al. (2007) had an error in the specification of sea ice fraction. This error has little impact on tropical cyclones but could have an impact on extratropical cyclones. This has motivated the integrations to be repeated for this study following the correction of the error. The results from the new T213 integration have been compared with those of the T63 coupled integration from which the SST were taken. Results are also contrasted with the 40-yr European Centre for Medium-Range Weather Forecasts (ECMWF) Re-Analysis (ERA-40; Uppala et al. 2005), which uses a T159 resolution $(125 \mathrm{~km}$, linear grid) to provide verification that the model is realistic in its simulation of extratropical cyclones in terms of their distribution and properties, including their three-dimensional (3D) structure and life cycle. A limited period of data (10 yr, 1989-98) from the new ECMWF interim reanalysis is also used for verification. This has a higher resolution than ERA-40 of T255 (80-km linear grid) and uses a four-dimensional variational data assimilation (4DVar) system. Reanalyses provide our best $4 \mathrm{D}$ view of the atmosphere, though they are strongly dependent on the observations and how they are assimilated (Bengtsson et al. 2004). Intercomparing reanalyses provides some degree of the level uncertainty. Intercomparing cyclones between different reanalyses suggests that in the NH the reanalyses are reasonably well constrained with differences mainly associated with resolution; however, in the $\mathrm{SH}$ there is considerably less agreement (Bromwich et al. 2007; Wang et al. 2005; Hodges et al. 2003).

The identification and tracking of the extratropical cyclones follows closely the study of Bengtsson et al. (2006). The approach makes use of the $850-\mathrm{hPa}$ relative vorticity field $\left(\xi_{850}\right)$ to identify and track the storms, the benefits of which are discussed in Hoskins and Hodges (2002). To enable reliable tracking of the storms the vorticity field is reduced in resolution to T42 and smoothed before identifying the cyclones (for details, see Hoskins and Hodges 2002). The T42 resolution also means that the identification is performed at a common spatial scale and thus allows a fairer comparison to be made between the T63 and T213 integrations. All seasons are considered but the emphasis of this study is on the $\mathrm{NH}$ winter activity.

Since the emphasis of this paper is on changes in extremes of winds and precipitation associated with extratropical cyclones, it is not necessary to consider every identifiable storm. In the past, posttracking filters have been applied to only retain cyclones with particular properties. For example, Bengtsson et al. (2006) only considered storms that lasted for more than 2 days and traveled further than a $1000 \mathrm{~km}$, while other studies have used different filters to retain or exclude more storms. We have retained the 2-day $1000-\mathrm{km}$ filter and tested that this has little impact on the study.

To see the full benefit of higher resolution and its impact on storm properties, the full-resolution properties must be extracted from the data along the storm trajectories. In the study of tropical cyclones of Bengtsson et al. (2007) this was done using a B-spline interpolation and optimization approach. However, because of the more asymmetrical nature of extratropical cyclones we have employed additional techniques. For the determination of pressure minima, associated with the vorticity tracks, we apply the original approach where the local minimization of the mean sea level pressure (MSLP) occurs within some prescribed radius of the storm center, while for winds and vorticity we just do a simple search for the maximum value within the search radius (minimum value of vorticity in the $\mathrm{SH}$ ). For variables, such as total precipitation, the area average is computed over the prescribed radius. The chosen storm-centered regions are spherical caps, with areas computed accordingly. The size of the chosen regions is somewhat arbitrary and several tests have been performed with different sizes. The wind and precipitation fields of extratropical cyclones can extend over quite large areas, if the trailing frontal systems are included, so it might be expected that a region with large radius would be needed to capture their full extent. After exploring different radii, a $5^{\circ}$ spherical arc radius was found to be adequate for capturing the extremes. Ideally the sampling region should depend on the storm size. While some previous studies have attempted to estimate this, using MSLP or geopotential, it still requires subjective decisions as to what constitutes the storm size. It is also likely to depend on the field used; that is, storms in vorticity are likely to look smaller than in MSLP.

We have also examined the typical life cycle and structure of storms using composites of a number of selected extreme storms. Life cycle composites are determined from the single-value properties along the selected tracks, centered relative to the time of maximum intensity, in the T42 $\xi_{850}$, and averaged. Regional composites 
are produced by extracting the regions around the storm centers on a radial grid and averaging these for particular stages of the storm life cycle. The radial grid is defined on a spherical region to prevent the kind of distortion that occurs when using projections. Additionally, the grid is aligned with the propagation direction of each individual storm by rotating the grid so that the grid preferred direction is aligned with the storm direction at each time step. Since the storm structure depends on its propagation, the consistent orientation of the storms will reduce the "smearing" of the composites. Full details can be found in the appendix of Bengtsson et al. (2007). Both types of composites are compared with the corresponding composites computed from extreme storms selected in the same way from the ERA-40 data for the satellite period (1979-2002).

In addition to examining the properties of the storms at single levels, we have also examined their full $3 \mathrm{D}$ vertical structure and vertical tilts. This is done by first determining the storm centers iteratively using the relative vorticity fields at a number of levels up to the tropopause (see Bengtsson et al. 2007). Each additional vorticity field is treated in exactly the same way as for the tracking. For the tilts the centers at each level are projected onto the storm direction (in spherical geometry) and the position relative to the $850-\mathrm{hPa}$ center determined as a geodesic angle. The composite life cycles are then computed as before. The multilevel centers can be used to produce $3 \mathrm{D}$ composites, taking the storm vertical tilt fully into account by extending the regional composites through the depth of the troposphere.

\section{Climatology and comparison with $\mathrm{T} 63$ and observations}

The storm climatology for the T213, 20C integration for the NH winter is shown for track density overlaid with mean intensity and genesis density in Figs. $1 \mathrm{~b}$ and 1d, respectively. These can be contrasted with the T63 coupled integration (Figs. 1a,b) for the same period from which the SST originate for the T213 integration. Figure 1 shows that there is a strong correspondence between the distribution of storms at the two resolutions as well as their genesis distributions. These can also be compared with the same distributions computed from ERA-40 and shown in Figs. 2a,c of Bengtsson et al. (2006). This indicates that the T213 and T63 integrations show quite realistic distributions of track and genesis density. The variability of storms in the ECHAM5 model, with respect to El Niño-Southern Oscillation (ENSO) forcing, was explored by Bengtsson et al. (2006), who found the correct signal was reproduced when compared with ERA-40 though somewhat to strong. We do not expect this to be any different with the T213 model as the identically same SST have been used. The biggest differences between T213 and T63 are seen in the mean intensities computed from the full-resolution $\xi_{850}$ values; these show the T213 mean intensities to be roughly twice as large as those at T63. In terms of the average number of storms, during the period, the two integrations are fairly similar with 135 storms per month, excluding the tropics (north of $25^{\circ}$ ) for T63 and 138 for T213. The fact that the identified numbers of storms for the T63 and T213 integrations are so similar might at first appear strange. Previous studies using cyclone tracking have suggested that more storms are identified with increasing resolution (Blender and Schubert 2000; Jung et al. 2006). However, if the identification is made at different resolutions then different spatial scales will be identified with smaller-scale storms identified at higher resolution (Blender and Schubert 2000).

To indicate how the resolution impacts a range of measures of intensity, Fig. 2 shows the full-resolution, maximum intensity distributions for both the T63 and T213 storms, during the NH DJF for 20C, using MSLP, $\xi_{850}, 925-\mathrm{hPa}$ wind speed, and area-averaged total precipitation. We have tended to use the $925-\mathrm{hPa}$ winds throughout this paper as a measure of near-surface winds because they represent the wind field above the surface boundary layer and are specifically calculated by the model. They are a more robust quantity than the model 10-m winds, which are diagnostically determined. The intensity measures are constructed by finding the maximum/minimum value of the relevant parameter, determined within the $5^{\circ}$ (geodesic) region, along each track and binning the values. Figure 2 shows that the T213 maximum intensities indicate consistently more intense storms than those for T63 for all measures. Comparison with ERA-40 for the satellite period (not shown) shows that the ERA-40 distributions lie consistently between that of the T63 and T213 distributions for these variables.

We have also contrasted the distribution of intense cyclones, in terms of their winds, between the Pacific and the Atlantic Ocean and between ECHAM5, T213, and ERA-40 and summarize the results in Table 1. As can be seen there is almost twice as many intense cyclones $(>50$ $\mathrm{m} \mathrm{s}^{-1}$ ) during DJF in the Atlantic than in the Pacific for the model. If we adjust for the generally weaker winds in ERA-40 $\left(>45 \mathrm{~m} \mathrm{~s}^{-1}\right)$ the result is similar. We suggest that the contrast between Atlantic and Pacific is mainly due to enhancements of the wind speed around southern Greenland as well as exposure to cold air masses from Greenland and northern Canada (and enhanced available potential energy) in the northern Atlantic. The interaction of synoptic-scale systems with the steep 
T63

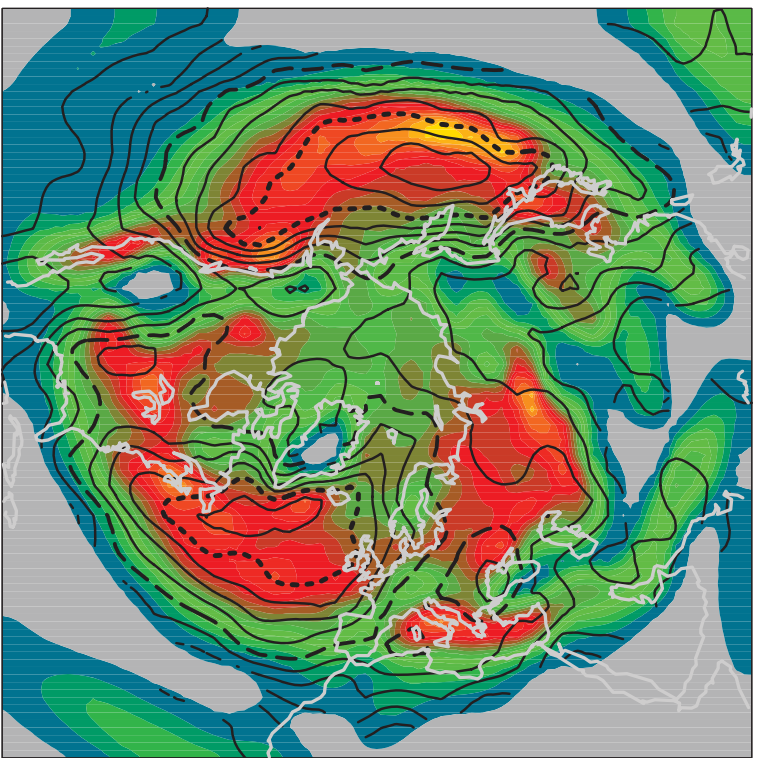

$--8 \times 10^{-5} s^{-1}$

(a)

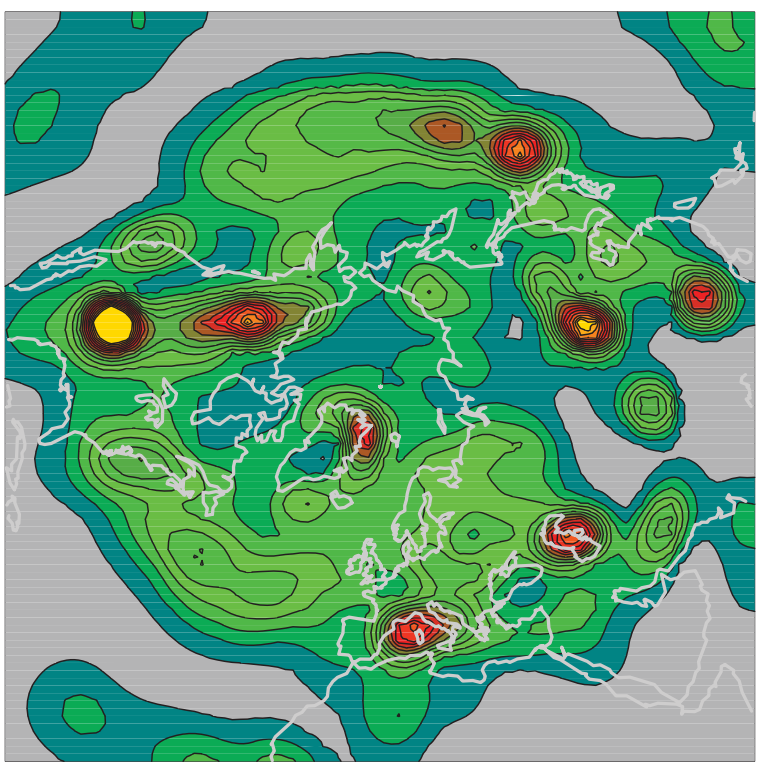

(c)
T213

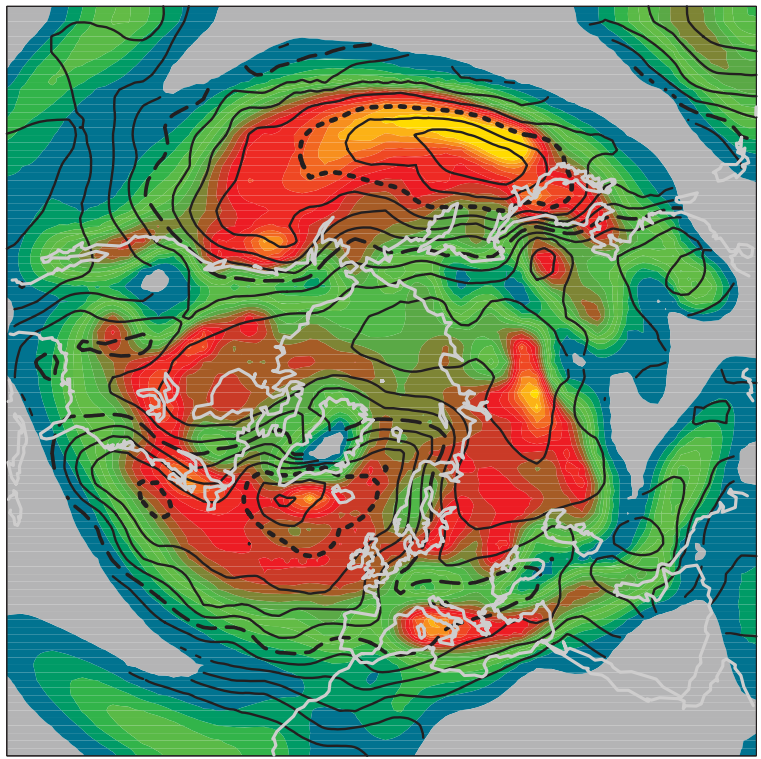

- $-20 \times 10^{-5} \mathrm{~s}^{-1} \quad \ldots \ldots-.30 \times 10^{-5} \mathrm{~s}^{-1}$

(b)

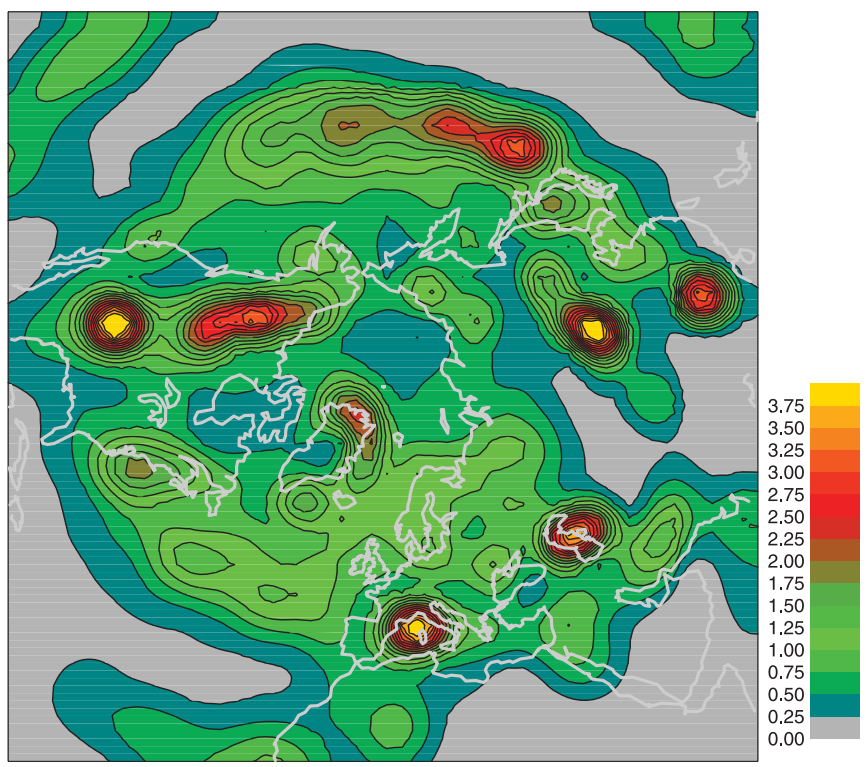

(d)

FIG. 1. Comparison of T63 and T213 tracking statistics for the DJF period for 20C: (a) T63 track density (color) overlaid with mean intensity (line contour) computed from full-resolution $\xi_{850}$, (b) T213 track density (color) overlaid with mean intensity (line contour) computed from full-resolution $\xi_{850}$, (c) T63 genesis density, and (d) T213 genesis density. Densities are as number density per month per unit area with the unit area equivalent to a $5^{\circ}$ spherical cap, and intensities are in units of $10^{-5} \mathrm{~s}^{-1}$ with a contour interval $(\mathrm{CI})$ of $1 \times 10^{-5} \mathrm{~s}{ }^{-1}$ for $\mathrm{T} 63$ and $2.5 \times 10^{-5} \mathrm{~s}^{-1}$ for T213.

orography of Greenland and the impact this has on the wind field has been studied by Moore and Renfrew (2005) using observations from the Quick Scatterometer (QuikSCAT) satellite. Comparison of these results with those of the T213 model shows that the model at high resolution is capable of simulating these winds much more realistically than the T63 model. Tsukernik et al. (2007) in a similar tracking study have also highlighted the complex interactions that can occur between developing synoptic systems and Greenland. 


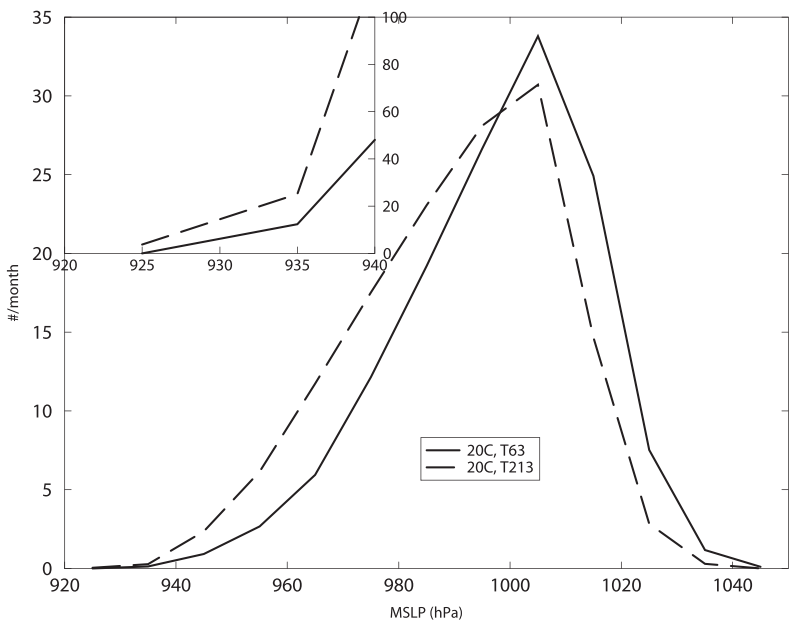

(a)

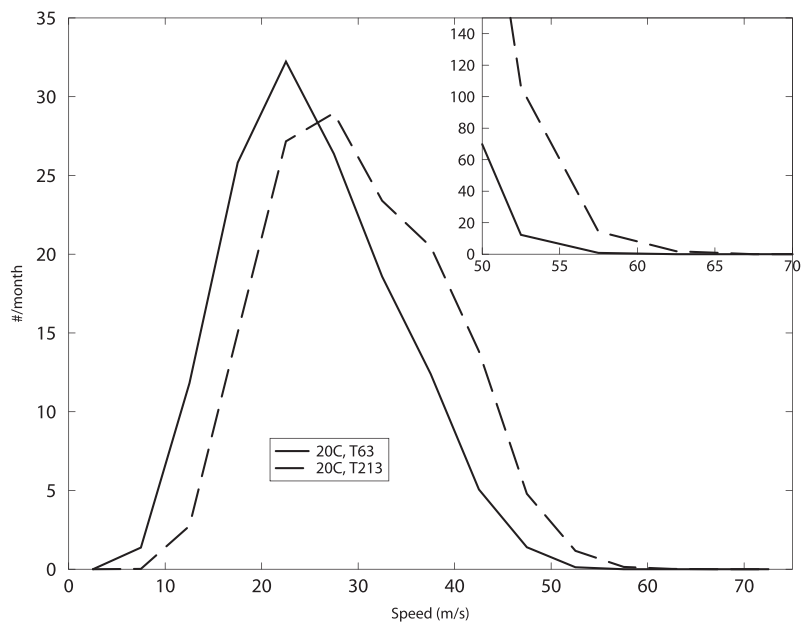

(c)

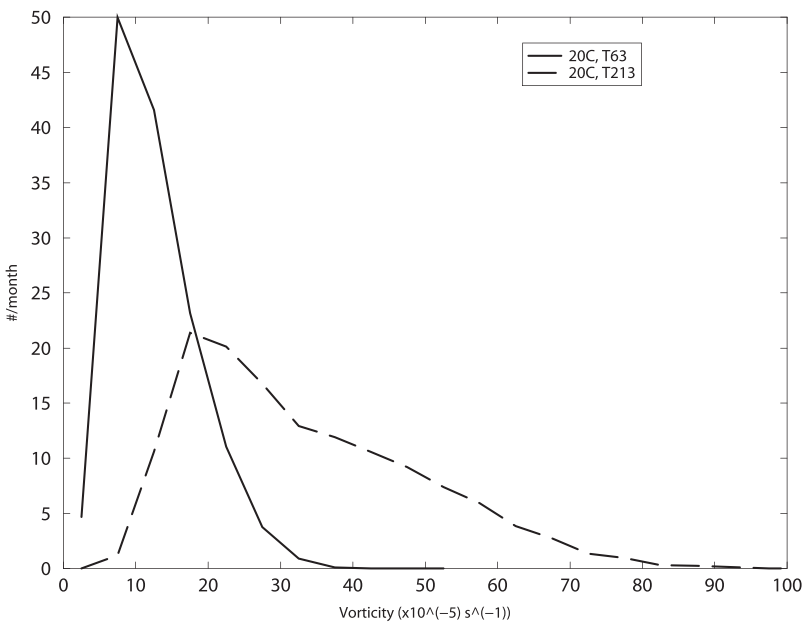

(b)

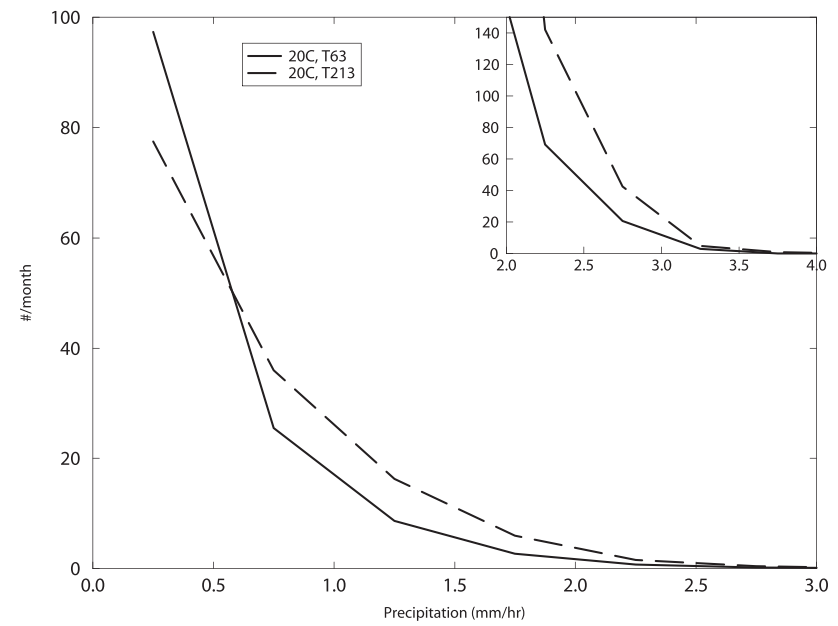

(d)

FIG. 2. Comparison of T63 and T213 intensity distributions for different parameters for the DJF period for 20C: (a) minimum MSLP ( $\mathrm{hPa}$ ), bin width (bw) is $10 \mathrm{hPa}$; (b) maximum $\xi_{850}\left(\times 10^{-5} \mathrm{~s}^{-1}\right)$, bw is $5\left(\times 10^{-5} \mathrm{~s}^{-1}\right)$; (c) maximum $925-\mathrm{hPa}$ wind speed $\left(\mathrm{m} \mathrm{s}^{-1}\right)$, bw is $5 \mathrm{~m} \mathrm{~s} \mathrm{~s}^{-1}$; (d) maximum area-averaged total precipitation $\left(\mathrm{mm} \mathrm{h}^{-1}\right)$, bw is $0.5 \mathrm{~mm} \mathrm{~h}^{-1}$. All parameters are determined with a $5^{\circ}$ spherical cap region centered on the T42 storm location for all storms north of $25^{\circ}$. The insets show the tails of the distributions scaled to 90 months (30 DJFs).

Though we prefer to use winds that are computed directly by the model, we have explored the 10 -m wind field to determine how realistic the values are at selected sites compared with observations. We have selected the Ekofisk oil platform in the central North Sea $\left(56.5^{\circ} \mathrm{N}, 3.2^{\circ} \mathrm{E}\right)$ as being representative. This allows us to compare with the results presented by Weisse et al. (2005, their Fig. 2) who used downscaling from reanalyses with a limited-area model over Europe at 50-km resolution to compare with observations. Figure 3 shows the DJF 10-m wind speed for the 90, 95, 99, and 99.5 percentiles for the nearest T213 model grid point to the Ekofisk station compared with ERA-40 and the observations. The observations have been sampled to the same 6-hourly frequency as the model and ERA-40 data. The model results agree well, in terms of magnitudes, with both observations and Weisse et al. (2005), whereas the ERA-40 10-m winds are in general less than those of the model and observations. This further provides us with confidence in the T213 model's capability to produce realistic results of the properties of extratropical cyclones both qualitatively and quantitatively.

\section{Structure of extratropical storms}

We have shown that the model is capable of producing credible spatial distributions of extratropical cyclones and their properties. Here we show that the model is also capable of simulating storms with a credible structure and evolution in time and space. This 
TABLE 1. Number of extreme storms in the NH, Atlantic, and Pacific for the DJF period for ERA-40 (1979-2001) and ECHAM5 (20C) normalized to $22 \mathrm{yr}$. $\mathrm{NH}\left(25^{\circ}, 90^{\circ} \mathrm{N}\right)$; Atlantic $\left(25^{\circ}, 70^{\circ} \mathrm{N}\right)$, $\left(280^{\circ}, 360^{\circ}\right)$; Pacific $\left(25^{\circ}, 70^{\circ} \mathrm{N}\right),\left(120^{\circ}, 240^{\circ}\right)$.

\begin{tabular}{lrcr}
\hline \hline & NH & Atlantic & Pacific \\
\hline ERA-40 $>45 \mathrm{~m} \mathrm{~s}^{-1}$ & 86 & 52 & 29 \\
ERA-40 $>50 \mathrm{~m} \mathrm{~s}^{-1}$ & 4 & 4 & 0 \\
ECHAM5 $>45 \mathrm{~m} \mathrm{~s}^{-1}$ & 393 & 197 & 188 \\
ECHAM5 $>50 \mathrm{~m} \mathrm{~s}^{-1}$ & 87 & 52 & 32 \\
\hline
\end{tabular}

provides further confidence in the model when it is used to assess changes in extratropical cyclones in a warmer climate. To study this we have explored the life cycle and structure of the extratropical storms in the T213 model and contrasted them with those in ERA-40 for the NH winter. Since the emphasis of the study is on intense cyclones, we have restricted the analysis to composites of the 100 most intense cyclones indentified from the T42 $\xi_{850}$. Any of the other intensity measures can be used as a means of selection, though they would not necessarily result in the same 100 storms. The T42 $\xi_{850}$ is used for the selection as it is the field used for the identification and tracking, is less noisy than the fullresolution vorticity, and has a good correspondence with the minimum pressure in the life cycle of the storms. To ensure there is sufficient overlap in the evolution of the storms, a further lifetime threshold is imposed so that storms must last for longer than 4 days. There may be more intense storms but because of their shorter lifetimes they would make the composites noisy if used.

For the life cycle compositing, each storm is centered on the time at which it reaches its maximum intensity in the T42 $\xi_{850}$, and we use the same variables as previously discussed in section 3, for both ECHAM5, 20C and ERA-40 for the satellite period. These are shown in Fig. 4a. For both ECHAM5 and ERA-40 the maximum pressure deepening rate can be seen to occur some $30 \mathrm{~h}$ prior to when the minimum pressure occurs. We note that the maximum in the full-resolution vorticity occurs prior to the minimum surface pressure by about $12 \mathrm{~h}$. This is to be expected as the scale of intense extratropical cyclones is such that the wind field is likely to lead the mass field in the geostrophic adjustment process (Temperton 1973). The time scale for this adjustment is broadly proportional to the inverse of the Coriolis force (Cahn 1945). The precipitation rapidly increases during the development of the cyclone reaching its maximum some $12-18 \mathrm{~h}$ before the cyclone reaches its minimum pressure. At that time the precipitation is in rapid decay as the cyclone occludes and the mechanism behind the lifting of the air is collapsing. In fact the rate of diminishing precipitation is faster than the rate of increase.
It is apparent that the composite life cycle shows that the rate of decay of the cyclone is nearly as large as the rate of intensification. This is not due to Reynolds stresses, as these are much too weak, in particular over the oceans where the strongest extratropical cyclones occur (Charney 1959, p. 188). Instead the rapid reduction of the cyclone's intensity is due to the divergence of geopotential height fluxes (Orlanski and Katzfey 1991).

The life cycle composites are in close agreement in all respects between the model and ERA-40 with the main difference that wind speed, vorticity, and precipitation are less intense in ERA-40. The deepening rate (as measured in surface pressure) is practically identical, reaching a maximum value of $1.5 \mathrm{hPa} \mathrm{h}^{-1}$, and clearly puts these storms into the class of "bombs" (Sanders and Gyakum 1980). This is a robust parameter as observations of surface pressure are assimilated in ERA-40. The difference in precipitation is some $20 \%$ less in ERA-40. We suggest this is mainly due to spinup effects in the ERA-40 as it represents precipitation during the first $6 \mathrm{~h}$ of the forecast. Other possible contributing factors to the weaker intensities in ERA-40 are the lower horizontal resolution and the use of a 3DVar data assimilation system. A preliminary assessment of cyclones in the new ECMWF Interim reanalysis has also been made. Since only $10 \mathrm{yr}$ are available to produce life cycle composites, we have only taken the 50 most intense storms for the NH, DJF. To contrast these with ERA-40 we have identified the identical same storms using a matching approach (Hodges et al. 2003) and produced the same composites. The Interim-ERA-40 comparison is shown in Fig. 4b. This shows similar results to those in Fig. 4a except that the Interim has greater intensities for all variables than ERA-40. The implication of this is that reanalyses at resolutions comparable to the T213 model, and using modern data assimilation methods, will be closer to the model. In fact reanalyses may underpredict intensities because of the data assimilation. Hence, we believe that the model is not per se overpredicting intensities (cf. Fig. 3).

The composite horizontal structure of the same 100 most intense storms in the model at different stages of their life cycle are shown in Fig. 5, with the composite storm moving to the right. Figures 5a,b show the composite structure of the cyclone in terms of the $925-\mathrm{hPa}$ wind field, total precipitation, MSLP, and mean temperature at the time of maximum intensification, in terms T42 $\xi_{850}$. A similar result is obtained using maximum intensification in surface pressure. As the composites are of 100 cyclones, they are somewhat smoothed out. The rapidly developing composite cyclone has a broad open warm sector where the strongest winds occur 


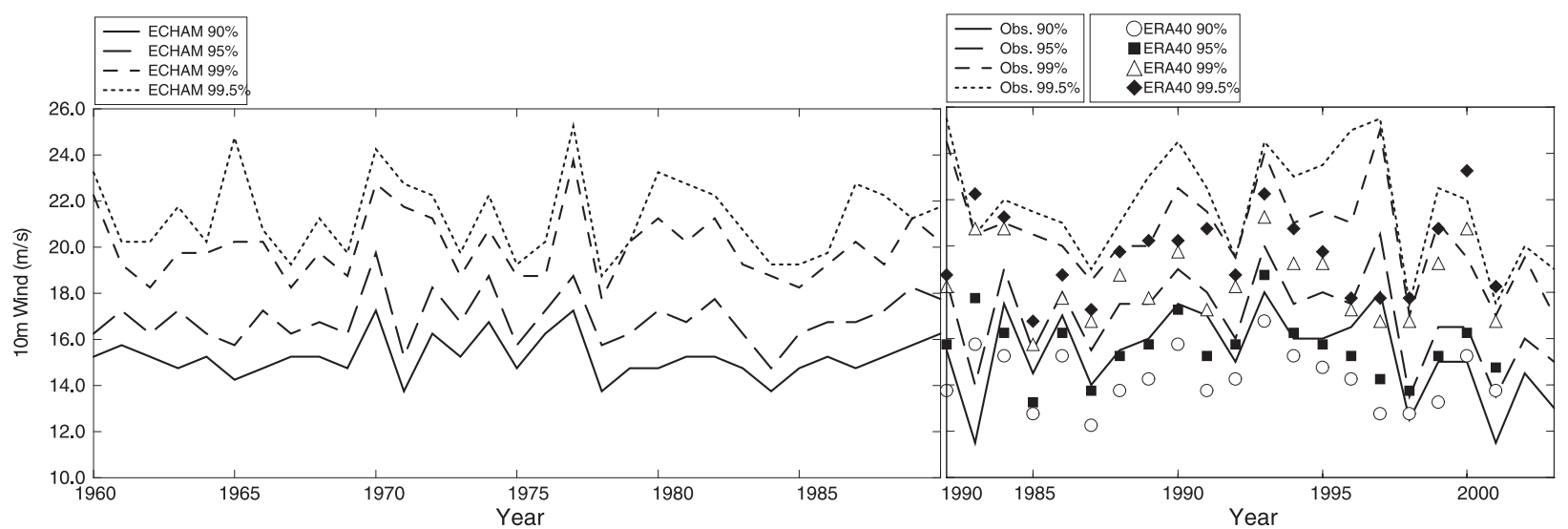

(a) ECHAM5

(b) Observations and ERA40

FIG. 3. Time series of the 10 -m winds for the Ekofisk platform in the central North Sea $\left(56.5^{\circ} \mathrm{N}, 3.3^{\circ} \mathrm{E}\right)$, for DJF centered on January, for the 90, 95, 99, and 99.5th percentiles at (a) the model grid point closest to the platform and (b) ERA-40 and the actual observations.

(Fig. 5a). The highest precipitation (Fig. 5b) occurs ahead of the center in the region of strong ascent as is typical for extratropical cyclones. Figures $5 \mathrm{c}$,d show the structure of the cyclone at the time of maximum precipitation. This occurs on average some $15 \mathrm{~h}$ after the time of maximum intensification. The wind field has strengthened and is orientated slightly differently with the wind maximum moving in an anticlockwise direction. Wind speeds above $25 \mathrm{~m} \mathrm{~s}^{-1}$ can now be seen practically all around the center of the cyclone. The area of maximum precipitation has higher values and extends further around the front of the cyclone. Finally in Figs. 5e,f we show the state of the cyclone at maximum intensity. The strongest winds are found behind and to the right of the cyclone in the area after the occluding cold front where maximum subsidence normally occurs. The field of precipitation is significantly weaker and is further distorted and extended around the cyclone in an anticlockwise direction. The same diagnostics are shown for ERA-40 in Fig. 6. This shows a similar progression in the wind and precipitation fields for the development of the composite storm to those in ECHAM5. However, as has already been noted, the ERA-40 values of wind and precipitation are generally lower, though the winds at maximum intensity are similar to those in ECHAM5. The MSLP shows an almost identical evolution and values to those for ECHAM5.

We have also explored the 3D structure of storms and their tilts, as described in section 2, using the same 100 storms. The 3D composites (not shown) are explored for the same stages of the storm life cycle as in Figs. 5 and 6 , and they confirm that the model is capable of reproducing similar structures for the different stages as ERA-40. A more detailed discussion is left to a future publication. The tilts are shown in Figs. $7 \mathrm{a}$ and $7 \mathrm{~b}$ for
ECHAM5 and ERA-40, respectively, for up to $36 \mathrm{~h}$ on either side of the maximum intensity. The tilt gradually increases as the composite storm grows (not shown) until it reaches a maximum upstream tilt $\sim 4^{\circ}$ between 850 and $200 \mathrm{hPa}$, roughly coincident with the maximum growth of the composite. After this it can be seen that there is a rapid change in the tilt occurring at the time when the storm has reached its maximum intensity and becomes barotropic. This rapid change to a basically barotropic state occurs over a period of $\sim 12 \mathrm{~h}$ and coincides with the rapid transition of the composite storm as discussed above. In fact the tilt can actually reverse as the storm occludes as seen in both Figs. 7a and 7b. This behavior is typical of the life cycle of an unstable baroclinic wave (Ogura 1957). Both the 3D composites and tilts indicate a good correspondence between ECHAM5 and ERA-40.

The composite storm results discussed in this section indicate that the model is realistic at simulating the baroclinic life cycle of extratropical cyclones when compared with storms identified in a modern reanalysis. This together with the results from section 3 provides us with confidence in using the model to explore extremes and their likely changes in a warmer climate. Note that, although the ECHAM and ECMWF models have a common origin, they have over time almost totally diverged in terms of dynamical core and parameterizations, so these favorable comparisons are not due to any commonality between the models.

\section{Effect of climate warming}

The main focus of this part of the study will be on the more serious aspects of extratropical cyclones, namely, extreme winds and precipitation, and any changes in a 


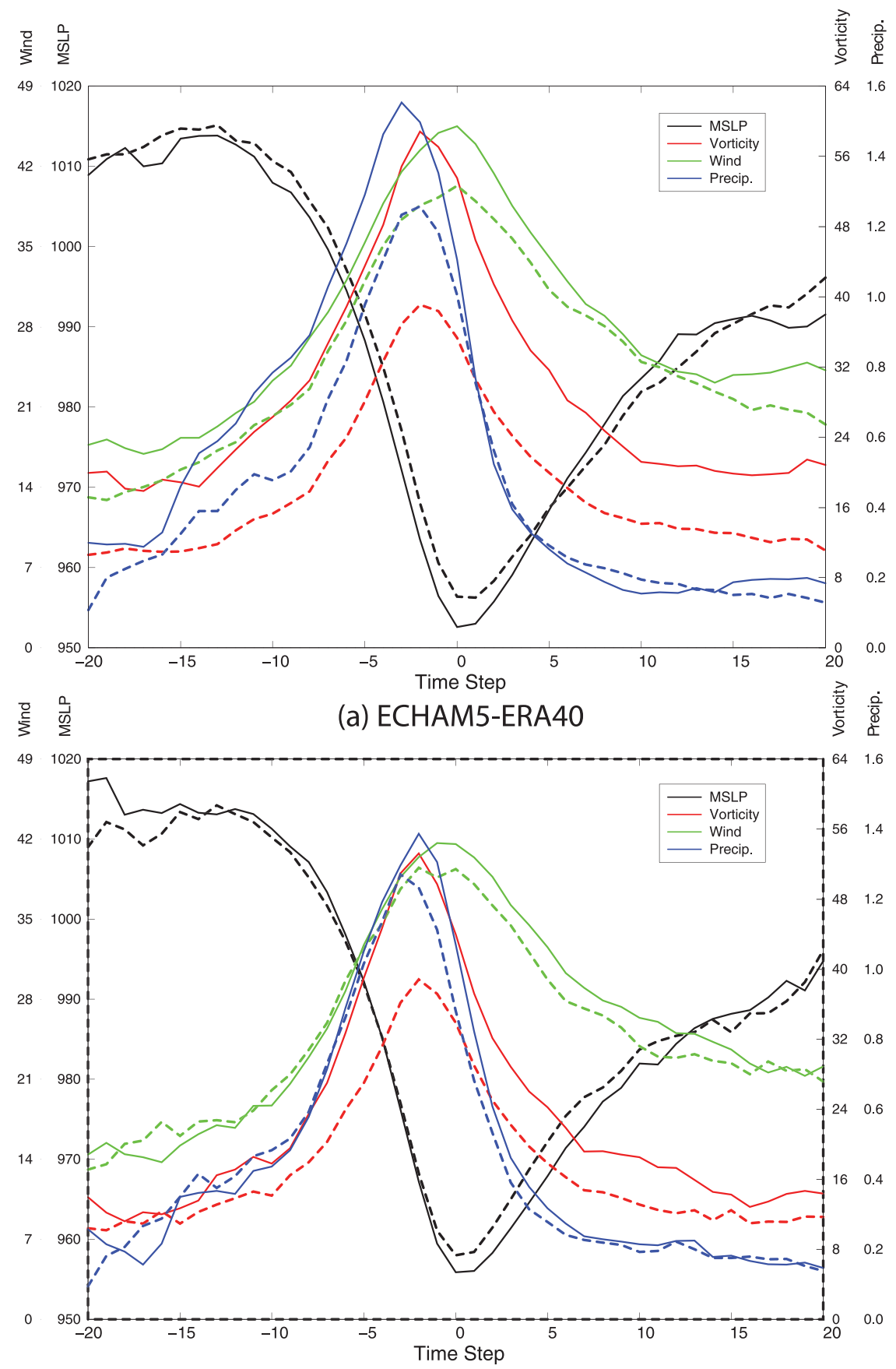

(b) Interim-ERA40

FIG. 4. (a) Life cycle composites of the 100 most intense storms, identified in T42 $\xi_{850}$, for the NH DJF for T213 ECHAM5 in 20C (solid line) and ERA-40 (1979-2002) (dashed line); (b) life cycle composites of the identically same 50 most intense storms in the Interim reanalysis (solid line) and ERA-40 (dashed line). Parameters shown are MSLP (hPa; black), $\xi_{850}\left(10^{-5} \mathrm{~s}^{-1}\right.$; red), 925-hPa winds ( $\mathrm{m} \mathrm{s}^{-1}$; green), and area-averaged total precipitation ( $\mathrm{mm} \mathrm{h}^{-1}$; blue). 

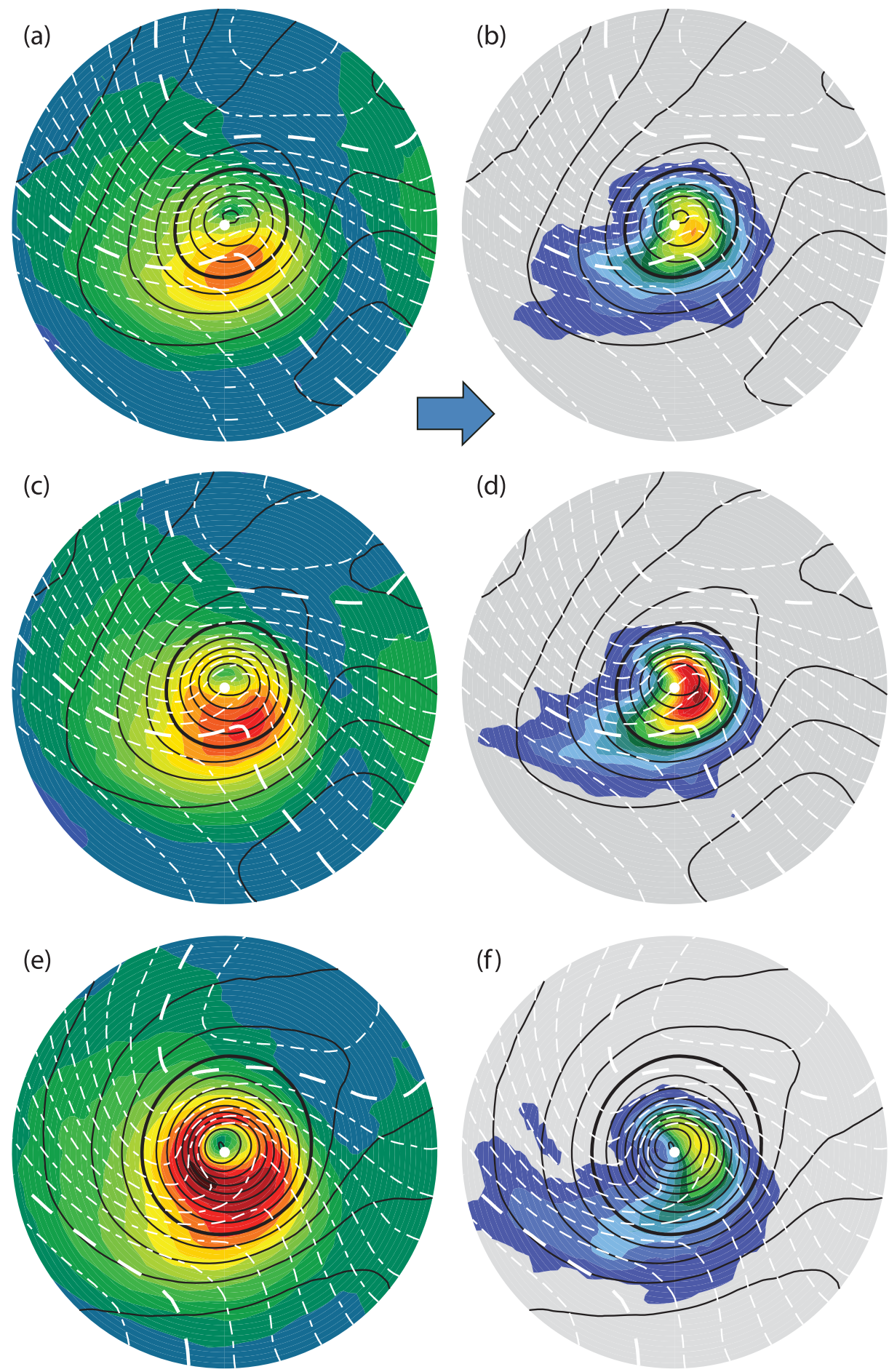

$\begin{array}{lllllllllllllllllllllllllllllllllll}0.0 & 2.5 & 5.0 & 7.5 & 10.0 & 12.5 & 15.0 & 17.5 & 20.0 & 22.5 & 25.0 & 27.5 & 30.0 & 32.5 & 35.0 & 37.5 & 0.0 & 0.2 & 0.4 & 0.6 & 0.8 & 1.0 & 1.2 & 1.4 & 1.6 & 1.8 & 2.0 & 2.2 & 2.4 & 2.6 & 2.8 & 3.0 & 3.2 & 3.4 & 3.6\end{array}$

FIG. 5. ECHAM5 composites on a $20^{\circ}$ radius region (geodesic) of the 100 most intense storms in T42 $\xi_{850}$ for the NH DJF at different life cycle stages; (top) maximum growth rate in T42 $\xi_{850}$, (middle) maximum precipitation, and (bottom) maximum T42 $\xi_{850}$ intensity. (left) The mean wind speed (color, $\mathrm{m} \mathrm{s}^{-1}$ ) overlaid with the mean MSLP (black contours, hPa) and the mean temperature between 850 and $500 \mathrm{hPa}$ (dashed white contours); (right) the mean precipitation (color, $\mathrm{mm} \mathrm{h}^{-1}$ ) with the same overlays. Thick MSLP contour is at $1000 \mathrm{hPa}, \mathrm{CI}$ is $5 \mathrm{hPa}$; thick mean temperature contours are at $250 \mathrm{~K}$ (upper line) and $270 \mathrm{~K}$ (lower line), CI is $2 \mathrm{~K}$. Arrow indicates direction of composite storm. 

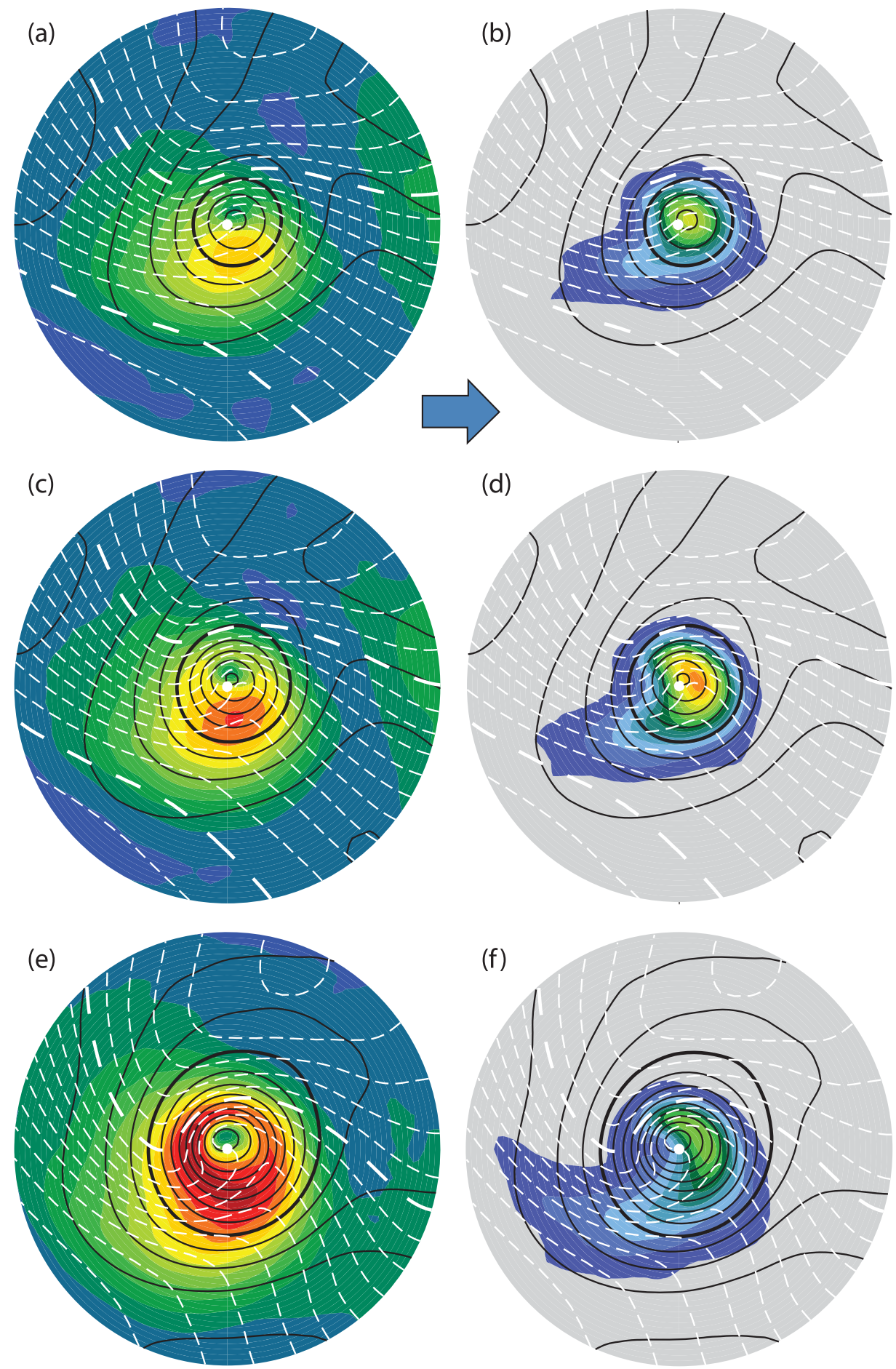

$\begin{array}{lllllllllllllllllllllllllllllllllllll}0.0 & 2.5 & 5.0 & 7.5 & 10.0 & 12.5 & 15.0 & 17.5 & 20.0 & 22.5 & 25.0 & 27.5 & 30.0 & 32.5 & 35.0 & 37.5 & 0.0 & 0.2 & 0.4 & 0.6 & 0.8 & 1.0 & 1.2 & 1.4 & 1.6 & 1.8 & 2.0 & 2.2 & 2.4 & 2.6 & 2.8 & 3.0 & 3.2 & 3.4 & 3.6\end{array}$

FIG. 6. Same as Fig. 5 but for ERA-40. 


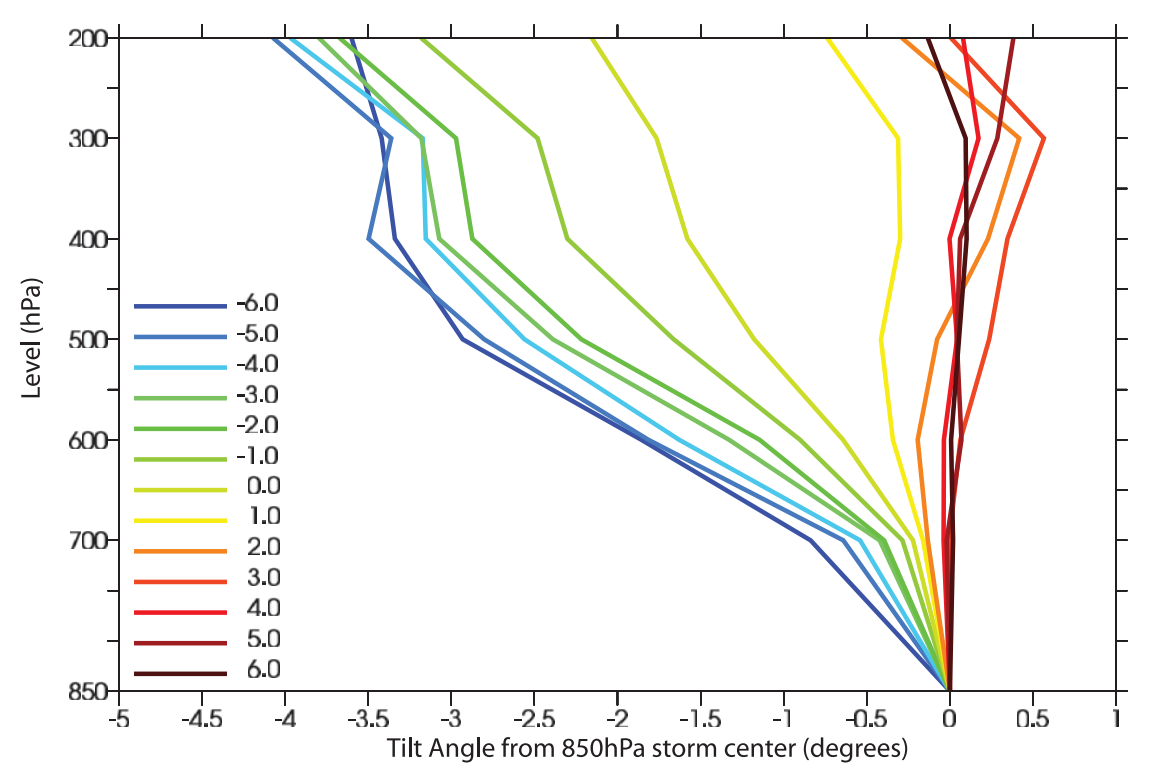

(a) ECHAM5

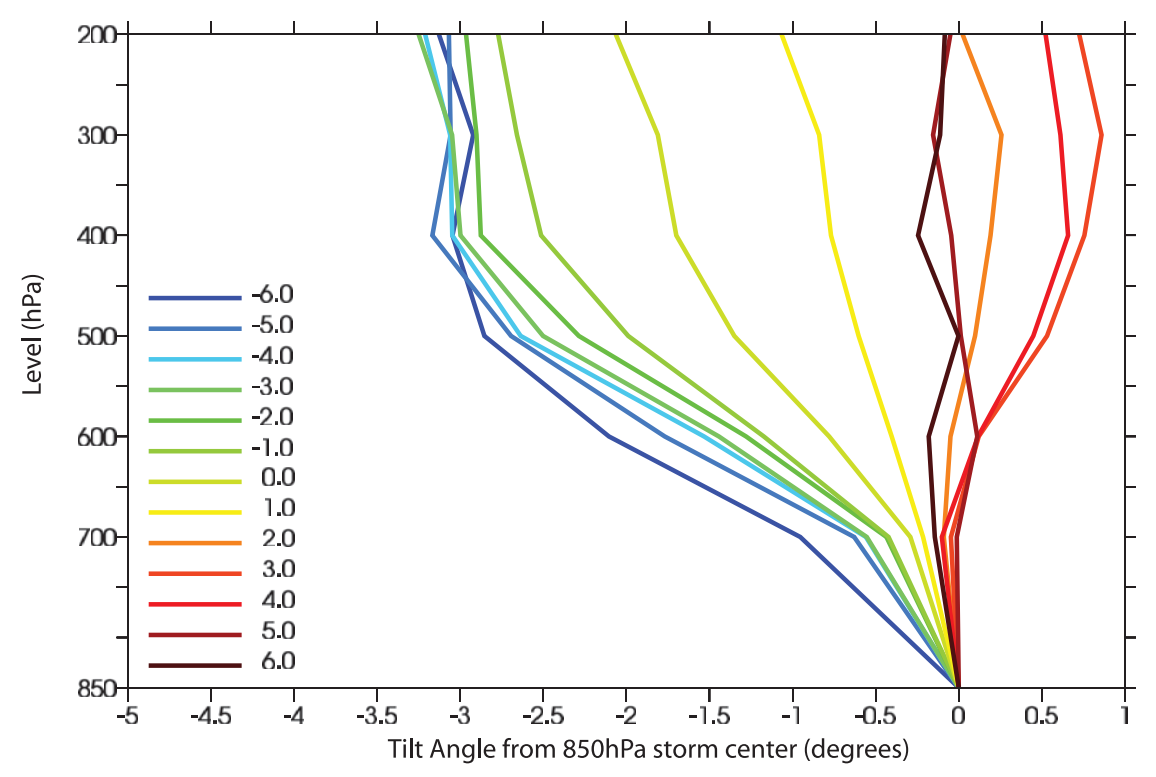

(b) ERA40

FIG. 7. Vertical tilt life cycle composites for the 100 most intense storms (identified in T42 $\left.\xi_{850}\right)$ for the NH DJF. Time steps are shown up to $36 \mathrm{~h}$ on either side of the maximum intensity for (a) ECHAM5 and (b) ERA-40. Tilts are in geodesic angle from the 850-hPa center.

warmer climate. In the previous section we concentrated on the analysis of the $\mathrm{NH}$ winter, here we extend the evaluation to all seasons and to both hemispheres. We first provide some general remarks on the changes in storms between 20C and 21C.

Compared to the previous study (Bengtsson et al. 2006) the changes in extratropical storm tracks between $20 \mathrm{C}$ and $21 \mathrm{C}$ are very similar (not shown), with a poleward migration in both hemispheres but most marked in the SH. Some differences between the T213 and T63 results do occur; however, we judge these differences to be within the variability of the T63 ensemble and longer observational datasets. Also consistent with the previous study the number of cyclones decreases by $\sim 3 \%-5 \%$ between $20 \mathrm{C}$ and $21 \mathrm{C}$. The reason for this is not clear, but could be due to a similar effect as we 
noted for the reduction in tropical cyclones, namely the general weakening of the vertical mass flux (Bengtsson et al. 2007). Other explanations could be the reduced temperature variance in the lower atmosphere. In general, the extreme extratropical cyclones have deeper central pressures in $21 \mathrm{C}$ than $20 \mathrm{C}$ (Fig. 8). Our interpretation of this is that this is mainly related to the poleward movement of the storm tracks. As the largescale surrounding pressure is generally lower, this will reduce the central surface pressure of the cyclones but does not enhance the wind speed (see Fig. 10), which is related to surface pressure gradients. The fact is that the maximum wind speed occurs when individual cyclones reach their lowest pressure. Other measures of the storm intensity can also be considered such as the T42 and full-resolution vorticities. The T42 $\xi_{850}$ shows similar distributions to those shown in Bengtsson et al. (2006), in particular the intensification of the more extreme systems in the SH during June-August (JJA) and September-November (SON) as the storm track moves poleward for $21 \mathrm{C}$. The full-resolution vorticity results are broadly consistent with the T42 results though the intensification in the $\mathrm{SH}$ is less obvious. Although differences, on the hemispheric regions so far discussed, indicate little change in the storm characteristics between 20C and 21C (apart from MSLP, associated with larger-scale changes), larger differences are apparent on more regional scales as previously shown by Bengtsson et al. (2006). Larger differences are also apparent for precipitation (see later).

Contrasting the life cycle composites of the 100 most intense extratropical cyclones, identified via the T42 $\xi_{850}$ intensities, in $21 \mathrm{C}$ with those in $20 \mathrm{C}$ for the $\mathrm{NH}$ winter (Fig. 9a), there is hardly any difference in vorticity with the peak wind speed slightly weaker. The minimum surface pressure on the other hand is a few hectopascals deeper and the peak precipitation is some $6 \%$ higher. In spite of the higher precipitation there is little effect on the maximum wind speed. The fact that the higher precipitation has limited impact on the intensity of the storms in terms of their wind speeds is emphasized if we redo the composite calculation but choose the 100 most intense precipitating storms, making sure not to include any storms of tropical origin, which behave dynamically differently. The results of this calculation, shown in Fig. 9b, show a greater increase in the peak level of precipitation $(\sim 10 \%)$ in $21 \mathrm{C}$ compared to 20C, but in terms of MSLP, vorticity, and winds the composite storm is actually weaker in $21 \mathrm{C}$. We suggest that the limited feedback of the increased precipitation on the intensity of the storms with respect to wind speeds, etc., is due to the distribution of the precipitation around the cyclone. This is not organized in such a way as to enhance the wind via a geostrophic effect. Moreover the change in the structure of the storm is very fast, in particular for precipitation, with the high precipitation decaying very rapidly as the storm occludes, the decay appears more rapid in $21 \mathrm{C}$. The distribution of the composite wind patterns, precipitation, and surface pressure at different stages of the storm life cycle for $21 \mathrm{C}$ (not shown) are virtually identical to what we have shown for 20C (Fig. 5).

In the following subsections we will consider the wind and precipitation in more detail. As well as exploring the winds and precipitation associated directly with the storms, we also explore these in gridpoint space by calculating the higher percentiles in the range of 95-99.9 using the 6-hourly data. This then gives the local change in extreme winds at every single point. Wind speed is the instantaneous value, while precipitation is the accumulated value over $6 \mathrm{~h}$. It is possible that more extreme conditions might occur within a 6-h interval, but we believe this is not important here as the objective is to compare conditions between $20 \mathrm{C}$ and $21 \mathrm{C}$. Furthermore, the instantaneous precipitation is not a robust quantity. We have explored the extreme winds identified by both the storm-centered and percentile methods and have convinced ourselves that there is a close association between the two and that the most extreme winds occur around the time when individual cyclones reach their maximum intensity. See Figs. 4 and 5.

\section{a. Wind field}

We investigate the wind at $925 \mathrm{hPa}$. As the main purpose of the study is to compare extreme winds in $20 \mathrm{C}$ and $21 \mathrm{C}$, we think this is a more reliable approach as this is a variable predicted by the model. It is also less influenced by the boundary layer and thus a more reliable predictor. Based on a wind regression relation between $925 \mathrm{hPa}$ and $10-\mathrm{m}$ winds determined from ERA-40 data we have found that $35 \mathrm{~m} \mathrm{~s}^{-1}$ at $925 \mathrm{hPa}$ is approximately equivalent to 10 Beaufort for the wind at $10 \mathrm{~m}$ and $45 \mathrm{~m} \mathrm{~s}^{-1}$ corresponds to approximately 12 Beaufort. These are used to explore extreme winds associated with cyclones.

We summarize the results for the $\mathrm{NH}$ in Tables 2 and 3 where we have listed the number of cyclones for different regions that reach maximum wind speed of 35 $\mathrm{m} \mathrm{s}^{-1}$ and $45 \mathrm{~m} \mathrm{~s}^{-1}$, respectively. For the $\mathrm{NH}$ as a whole there is a reduction in the number of cyclones, with wind speeds $>35 \mathrm{~m} \mathrm{~s}^{-1}$, for all seasons except JJA but the difference is hardly significant with the exception of the Atlantic. There is a general reduction over southern Europe and an increase over the Arctic. The larger number of events in the Arctic in $21 \mathrm{C}$ may be related to 


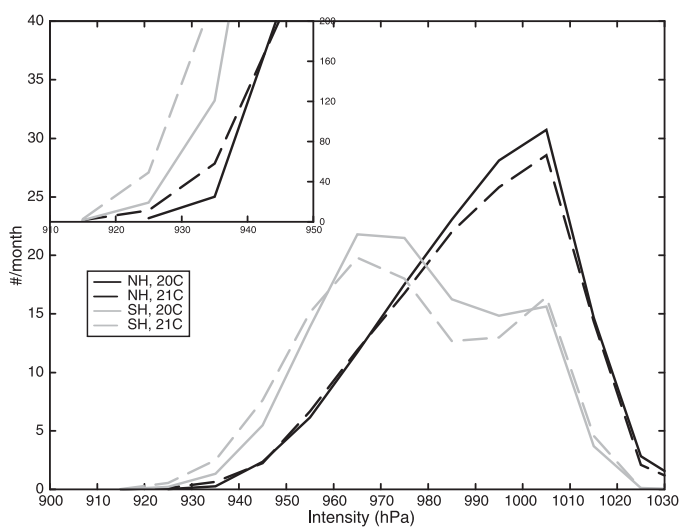

(a)DJF

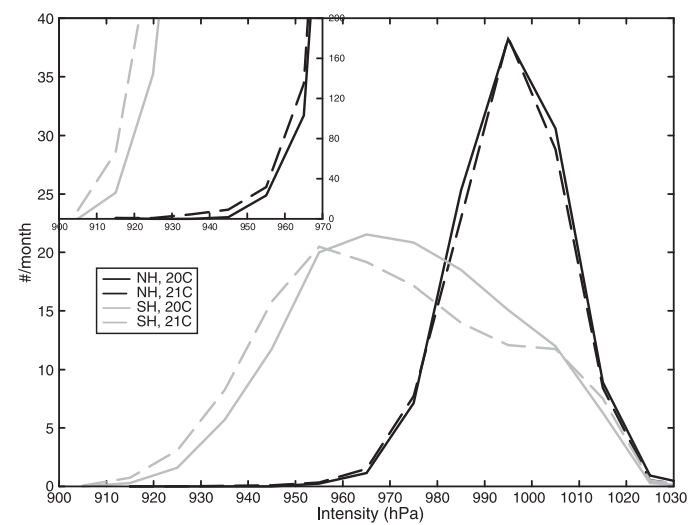

(c) JJA

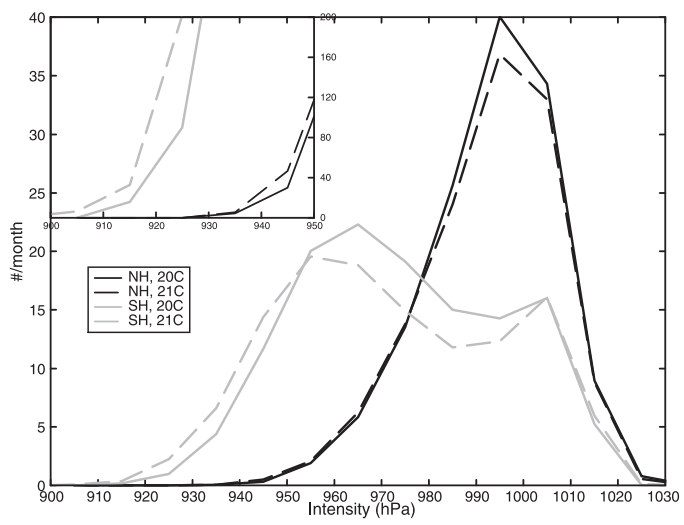

(b) MAM

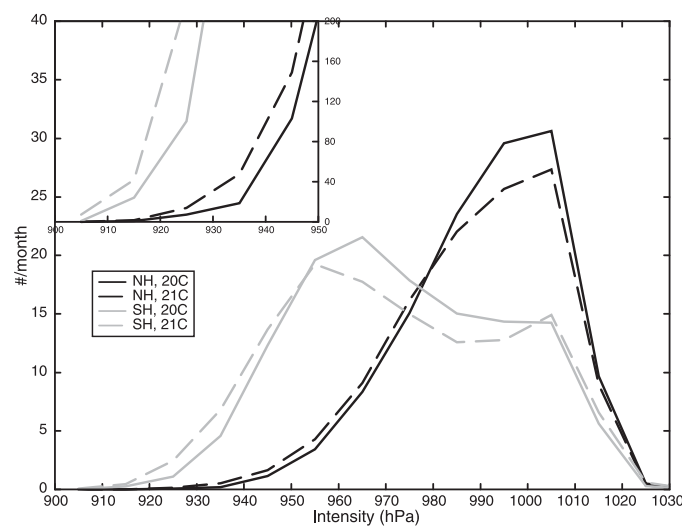

(d) SON

FIG. 8. Distributions of minimum pressure (hPa) computed along each cyclone track for both the NH (black) and SH (gray) and for 20C (solid) and 21C (dashed). (a) DJF, (b) MAM, (c) JJA, and (d) SON. Insets show the tails scaled to 90 months. Bin width is $10 \mathrm{hPa}$.

the reduced sea ice cover providing more favorable conditions for higher wind speeds. Minor changes can be found over northern Europe $\left(>35 \mathrm{~m} \mathrm{~s}^{-1}\right)$. The only significant increase is the increased number of stronger cyclones in winter for winds $>45 \mathrm{~m} \mathrm{~s}^{-1}$. The more extreme winds over northern Europe in winter can also be seen in the gridpoint distribution of the higher percentiles (see later). The more extreme wind speeds $(>45$ $\mathrm{m} \mathrm{s}^{-1}$ ) occur predominantly over the Atlantic and Pacific Oceans. The numbers of storms that have a purely extratropical origin are shown in brackets in Tables 2 and 3 . This has been done by excluding any systems with a tropical origin by removing any system that has its genesis in $25^{\circ} \mathrm{N}, 0^{\circ}$. This indicates that tropical storms undergoing extratropical transition have a strong influence in the summer and autumn months, particularly in the western Pacific region.

In Fig. 10 we show the maximum wind speed for all storm tracks for all seasons and for the extratropics of both hemispheres. The extreme winds for the $\mathrm{NH}$ are stronger for 20C during DJF and March-May (MAM). We have explored this in detail and it seems mostly to emanate from the eastern and southern coast of Greenland. This is apparent in Fig. 11 where the locations at which storms attain their maximum wind speed are displayed for maximum attained wind speeds $>45$ $\mathrm{m} \mathrm{s}^{-1}$ for the $\mathrm{NH}$ winter. As the Atlantic storms approach Greenland, the combination of steep orography and sharp coastline contrast leads to a secondary wind maximum at the northern and northwestern side of the storms. These intense winds are seen to be reduced in $21 \mathrm{C}$ compared with $20 \mathrm{C}$ as the Atlantic storm track changes its orientation away from Greenland. For 20C there is a clearer distinction between two preferred storm tracks, one northeast over the Norwegian Sea and another one eastward over the Mediterranean. At 21C the storm tracks have a preference for an intermediate storm track over the British Isles. The cause of this change is not clear but is partly an effect of the poleward transition of the Hadley circulation and an associated 


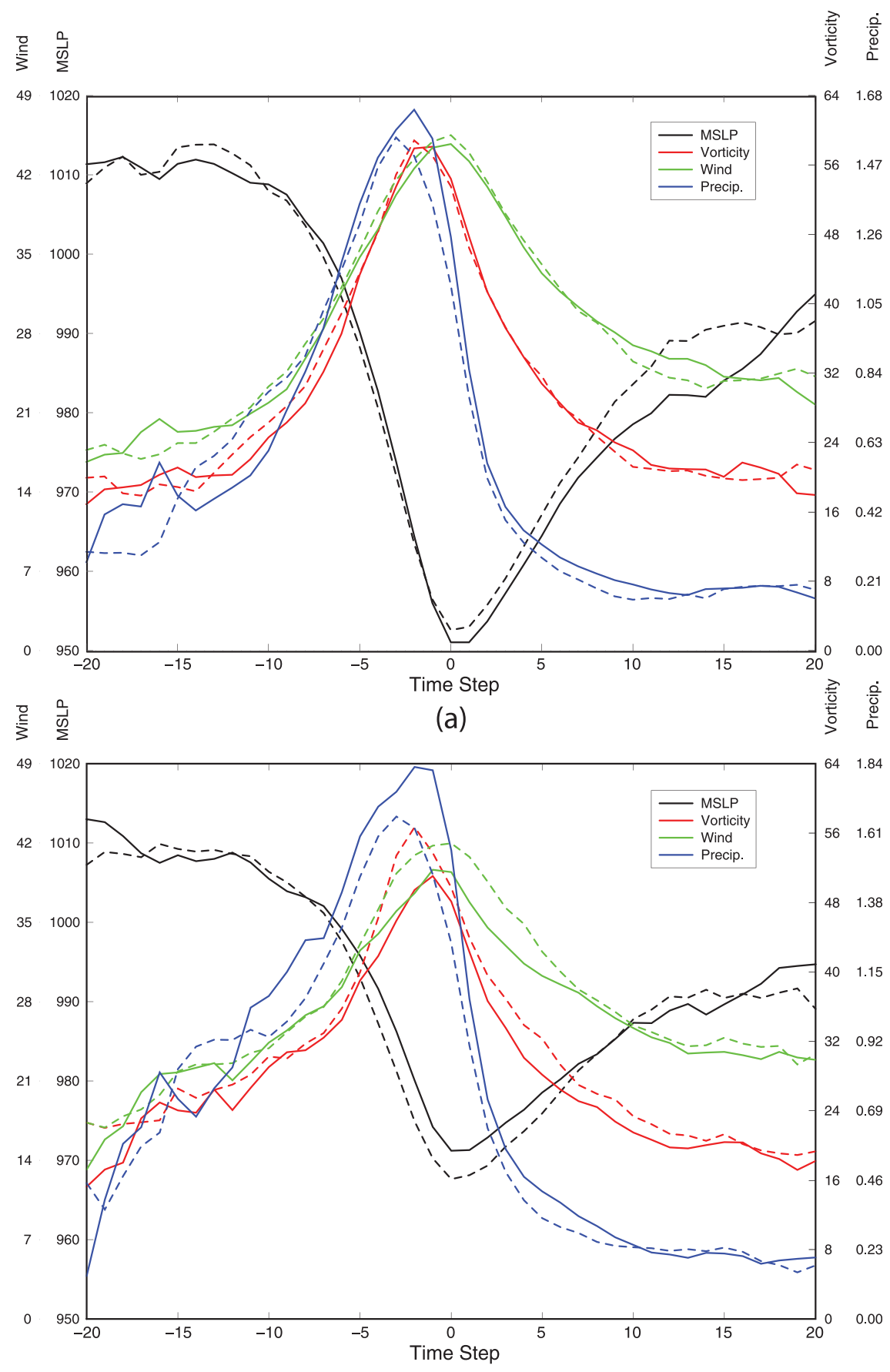

(b)

FIG. 9. Life cycle composites of the 100 most intense storms for the NH DJF for T213 ECHAM5 in 21C (solid line) and 20C (dashed line) identified from (a) their T42 $\xi_{850}$ intensities and (b) their area-averaged precipitation intensities excluding any systems with tropical origins. Parameters shown are MSLP $(\mathrm{hPa}), \xi_{850}\left(10^{-5} \mathrm{~s}^{-1}\right), 925-\mathrm{hPa}$ winds $\left(\mathrm{m} \mathrm{s}^{-1}\right)$, and area-averaged total precipitation $\left(\mathrm{mm} \mathrm{h}^{-1}\right)$. 
TABLE 2. Number of extreme storms in the NH for all seasons (numbers are for all $32 \mathrm{yr}, 31$ for DJF) with wind speeds above $35 \mathrm{~m} \mathrm{~s}^{-1}$ for various regions and for $20 \mathrm{C}$ and $21 \mathrm{C}$. $\mathrm{NH}\left(25^{\circ}, 90^{\circ} \mathrm{N}\right)$; Atlantic $\left(25^{\circ}, 70^{\circ} \mathrm{N}\right),\left(80^{\circ} \mathrm{W}, 0^{\circ}\right)$; Atlantic-western Europe $\left(25^{\circ}, 70^{\circ} \mathrm{N}\right),\left(90^{\circ} \mathrm{W}\right.$, $\left.40^{\circ} \mathrm{E}\right)$; Pacific $\left(25^{\circ}, 70^{\circ} \mathrm{N}\right),\left(120^{\circ} \mathrm{E}, 120^{\circ} \mathrm{W}\right)$; Arctic $\left(70.0^{\circ}, 90.0^{\circ} \mathrm{N}\right)$; northern Europe $\left(47.5^{\circ}, 70.0^{\circ} \mathrm{N}\right),\left(10^{\circ} \mathrm{W}, 40^{\circ} \mathrm{E}\right)$; southern Europe $\left(30.0^{\circ}\right.$, $\left.47.5^{\circ} \mathrm{N}\right),\left(10^{\circ} \mathrm{W}, 40^{\circ} \mathrm{E}\right)$. Values in brackets are excluding systems of tropical origin (those that have their genesis in $\left.25^{\circ} \mathrm{N}, 0^{\circ}\right)$.

\begin{tabular}{|c|c|c|c|c|c|c|c|c|}
\hline \multicolumn{9}{|c|}{$>35 \mathrm{~m} \mathrm{~s}^{-1}$} \\
\hline & & $\mathrm{NH}$ & Atlantic & Atlantic-Europe & Pacific & Arctic & Northern Europe & Southern Europe \\
\hline \multirow[t]{2}{*}{ DJF } & $20 \mathrm{C}$ & 3761 (3650) & 1454 (1413) & $1540(1498)$ & 2065 (1996) & $257(257)$ & 305 (304) & $70(70)$ \\
\hline & $21 \mathrm{C}$ & 3593 (3481) & 1323 (1288) & 1404 (1369) & 1995 (1918) & $300(299)$ & $271(270)$ & $52(52)$ \\
\hline \multirow[t]{2}{*}{ MAM } & $20 \mathrm{C}$ & $2226(2111)$ & $819(791)$ & $871(840)$ & $1256(1174)$ & $115(115)$ & $99(98)$ & $33(29)$ \\
\hline & $21 \mathrm{C}$ & 2181 (2081) & $760(749)$ & $823(808)$ & $1229(1146)$ & $141(141)$ & 77 (77) & $31(29)$ \\
\hline \multirow[t]{2}{*}{ JJA } & $20 \mathrm{C}$ & $878(622)$ & $349(325)$ & $377(350)$ & $455(238)$ & $26(26)$ & $15(15)$ & $0(0)$ \\
\hline & $21 \mathrm{C}$ & $922(652)$ & 304 (287) & $353(336)$ & $513(272)$ & $34(34)$ & $13(13)$ & $0(0)$ \\
\hline \multirow[t]{2}{*}{ SON } & $20 \mathrm{C}$ & 2575 (2233) & $1000(909)$ & 1071 (979) & 1339 (1162) & $146(145)$ & $179(168)$ & $23(22)$ \\
\hline & $21 \mathrm{C}$ & 2425 (2064) & $991(886)$ & $1057(949)$ & 1264 (1028) & 138 (136) & 207 (197) & $21(21)$ \\
\hline
\end{tabular}

weakening of the storm track over southern Europe. The enhancement of the storm track west of the British Isles we suggest is related to the strengthening SST gradient south of $50^{\circ} \mathrm{N}$ in the central Atlantic (Bengtsson et al. 2006). For the JJA and SON periods the extreme winds are marginally stronger for $21 \mathrm{C}$. We have examined this and found that the main cause is a contribution from stronger tropical cyclones entering the extratropics (see also Tables 2 and 3). There is practically no difference in the extreme winds for the SH over the whole hemisphere, though regional changes are seen associated with the poleward transition of the storm tracks.

If we now consider the gridpoint perspective, Fig. 12 shows the change in wind speed between $21 \mathrm{C}$ and $20 \mathrm{C}$ for the 99.5th percentile (about two events every winter); the other percentiles are structurally similar. We show this for both hemispheres and for $\mathrm{NH}$ winter and summer. As has been found in most previous studies (Ulbrich et al. 2008, and references therein) during the $\mathrm{NH}$ winter period there is a minor increase, $\sim 1 \mathrm{~m} \mathrm{~s}^{-1}$, in an area stretching from the central North Atlantic toward northern Europe covering a region between $40^{\circ}$ and $65^{\circ} \mathrm{N}$. This coincides with an enhanced storm-track density in the region for $21 \mathrm{C}$ (Bengtsson et al. 2006). In the area north and south thereof there is a reduction.
Other areas of increase in winds are the eastern United States and Canada, the Arctic, and eastern Asia. Large reductions occur south of $40^{\circ} \mathrm{N}$ in both the Atlantic and Pacific and in the Mediterranean region. In our previous paper (Bengtsson et al. 2006) we noted an intensification of the storm tracks between $45^{\circ}$ and $65^{\circ} \mathrm{N}$ over Europe and similar results have been found in other studies (Ulbrich et al. 2008). The result is similar at this higher resolution, hence the increase in extreme events in western Europe is due to a regional enhancement in storm-track density and intensity. This is likely related to increased low-level baroclinicity caused by an enhanced low-level temperature gradient in the central North Atlantic related to the region of reduced SST warming south of Greenland (Bengtsson et al. 2006). During the NH summer there is a general weakening for $21 \mathrm{C}$ in the Atlantic sector, while the Arctic has slightly stronger winds. In the Pacific there is an apparent increase, which as discussed previously we associate with changes in the intensities of tropical cyclones migrating poleward. In the $\mathrm{SH}$ we see a clear transition of more extreme winds toward the pole following the overall transition of the storm tracks toward higher latitudes, as pointed out in Bengtsson et al. (2006). This transition occurs for all seasons.

TABLE 3. Same as Table 2 but for wind speeds above $45 \mathrm{~m} \mathrm{~s}^{-1}$

\begin{tabular}{|c|c|c|c|c|c|c|c|c|}
\hline \multicolumn{9}{|c|}{$>45 \mathrm{~m} \mathrm{~s}^{-1}$} \\
\hline & & $\mathrm{NH}$ & Atlantic & Atlantic-Europe & Pacific & Arctic & Northern Europe & Southern Europe \\
\hline \multirow[t]{2}{*}{ DJF } & $20 \mathrm{C}$ & $573(546)$ & $286(277)$ & $286(277)$ & $274(256)$ & $15(15)$ & $14(14)$ & $1(1)$ \\
\hline & $21 \mathrm{C}$ & $552(517)$ & $264(251)$ & $267(254)$ & $277(255)$ & $16(16)$ & $22(22)$ & $1(1)$ \\
\hline \multirow[t]{2}{*}{ MAM } & $20 \mathrm{C}$ & $226(208)$ & 107 (105) & $108(106)$ & $112(96)$ & $9(9)$ & $2(2)$ & $0(0)$ \\
\hline & $21 \mathrm{C}$ & $193(175)$ & $77(76)$ & $78(77)$ & $111(95)$ & $3(3)$ & $1(1)$ & $0(0)$ \\
\hline \multirow[t]{2}{*}{ JJA } & $20 \mathrm{C}$ & $60(16)$ & $16(13)$ & $17(13)$ & $43(3)$ & $0(0)$ & $0(0)$ & $0(0)$ \\
\hline & $21 \mathrm{C}$ & $88(17)$ & $18(10)$ & $18(10)$ & $67(7)$ & $0(0)$ & $0(0)$ & $0(0)$ \\
\hline \multirow[t]{2}{*}{ SON } & $20 \mathrm{C}$ & $418(272)$ & $173(141)$ & $176(144)$ & $227(122)$ & $8(7)$ & $12(11)$ & $0(0)$ \\
\hline & $21 \mathrm{C}$ & 409 (249) & $174(125)$ & $178(126)$ & $221(122)$ & $3(3)$ & $11(7)$ & $1(1)$ \\
\hline
\end{tabular}




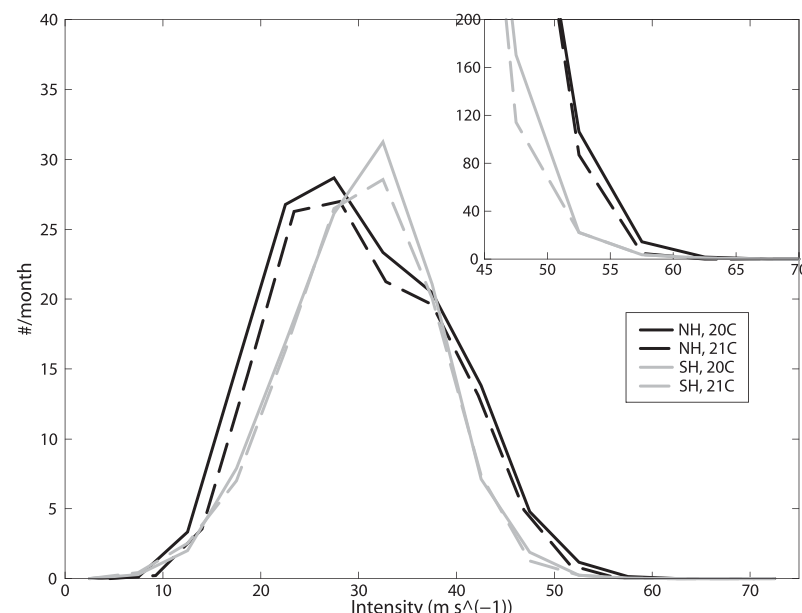

(a) DJF

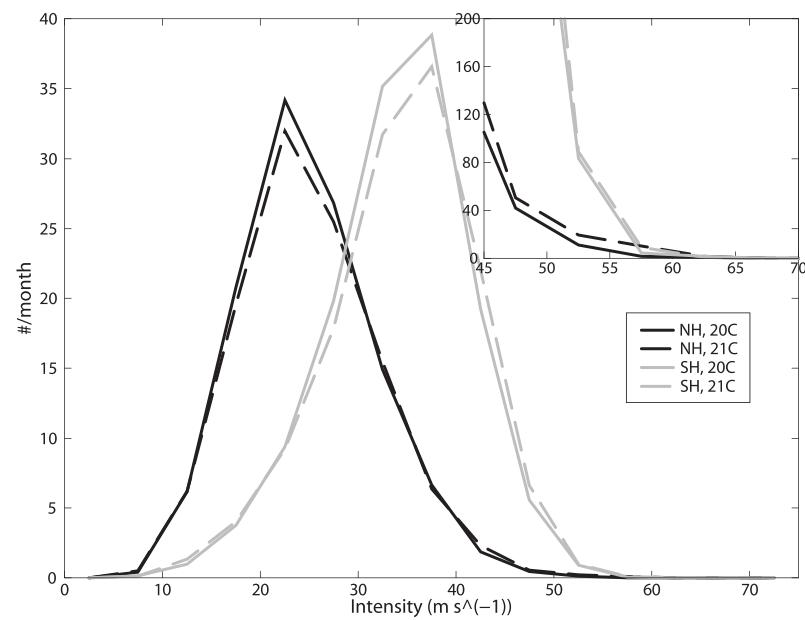

(c) JJA

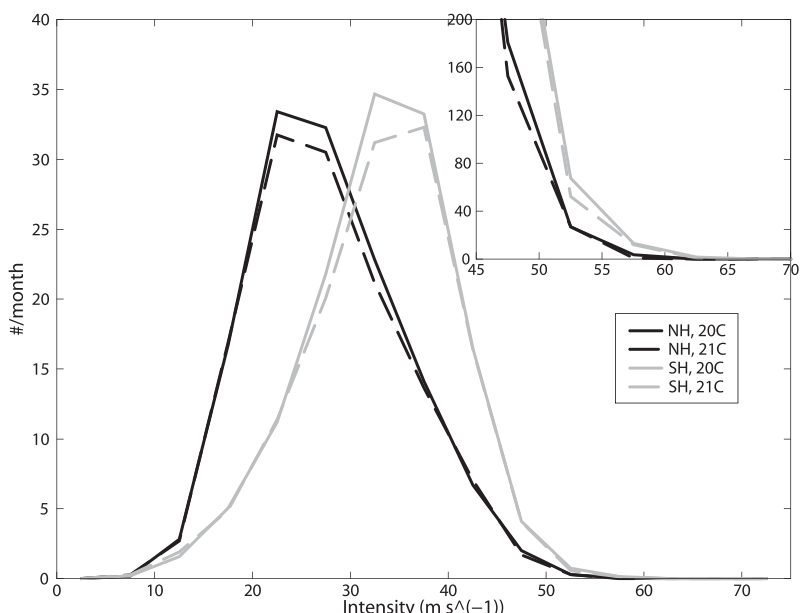

(b) MAM

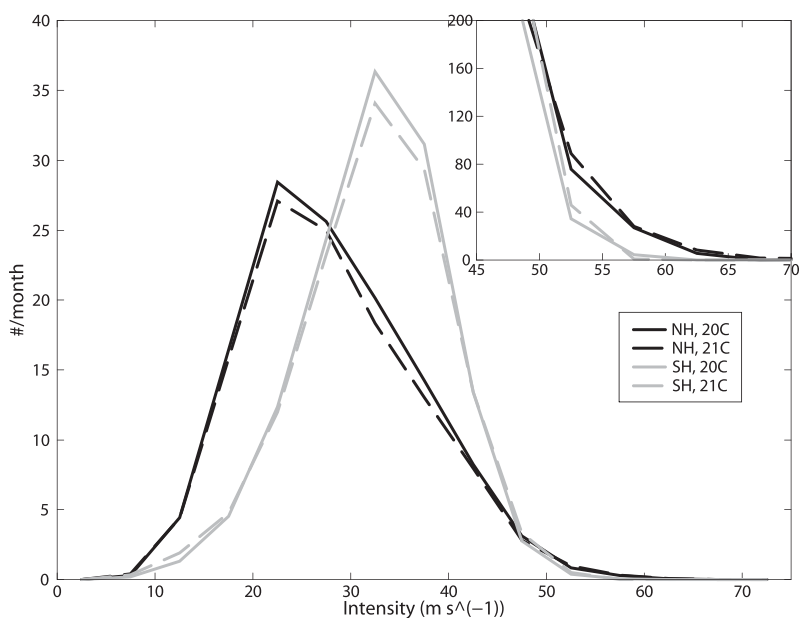

(d) SON

FIG. 10. Same as Fig. 8 except for maximum winds $\left(\mathrm{m} \mathrm{s}^{-1}\right)$. Bin width is $5 \mathrm{~m} \mathrm{~s}^{-1}$.

At first sight the results from the percentile analysis are at variance with the tracking analysis shown in Fig. 10, but in reality the differences are easily explained by the fact that the percentile analysis is an Eulerian analysis, which is sensitive to where the storms are found and hence to the shift in the storm tracks poleward as discussed. Figure 10 indicates that there are no major changes in the intensities of the storms over a hemisphere. In fact if we compare the results in Fig. 12 with the spatial statistics from the tracking, using the wind speed for intensity, then the changes in mean intensity are seen to be consistent with the changes in percentiles.

\section{b. Precipitation}

The global annual increase in precipitation is $6.2 \%$ in $21 \mathrm{C}$ compared to $20 \mathrm{C}$ or $1.9 \% \mathrm{~K}^{-1}$ global warming. For column water, on the other hand, the increase is $26.8 \%$ or $8.3 \% \mathrm{~K}^{-1}$. This increase of column water follows closely the Clausius-Clapeyron relation (Pierrehumbert et al. 2007; Held and Soden 2006).

The increase in maximum precipitation (as seen in gridpoint space) follows closely the increase in water vapor between $20 \mathrm{C}$ and $21 \mathrm{C}$. The global increase is $32 \%$ $\left(7.09 \mathrm{~mm} \mathrm{~h}^{-1}\right.$ at $21 \mathrm{C}$ versus $5.36 \mathrm{~mm} \mathrm{~h}^{-1}$ at $\left.20 \mathrm{C}\right) . \mathrm{Al}-$ though the increase varies it is slightly higher in the tropics than in the extratropics (39\% versus $29 \%$ ) but is again generally higher along the storm tracks. For the cyclone tracks the cumulative total precipitation along the track, within a $5^{\circ}$ geodesic radius, is higher than the total global increase in precipitation or $11.1 \%(28.8 \mathrm{~mm}$ per track versus $25.9 \mathrm{~mm}$, area averaged) but not as high as for the extreme (maximum) precipitation, which 


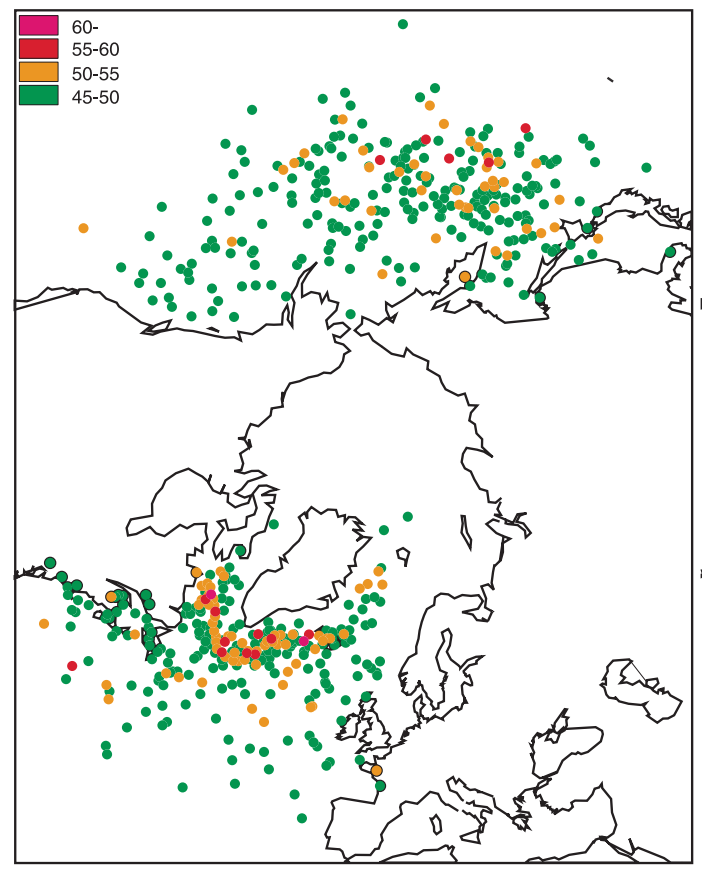

(a) $20 \mathrm{C}$

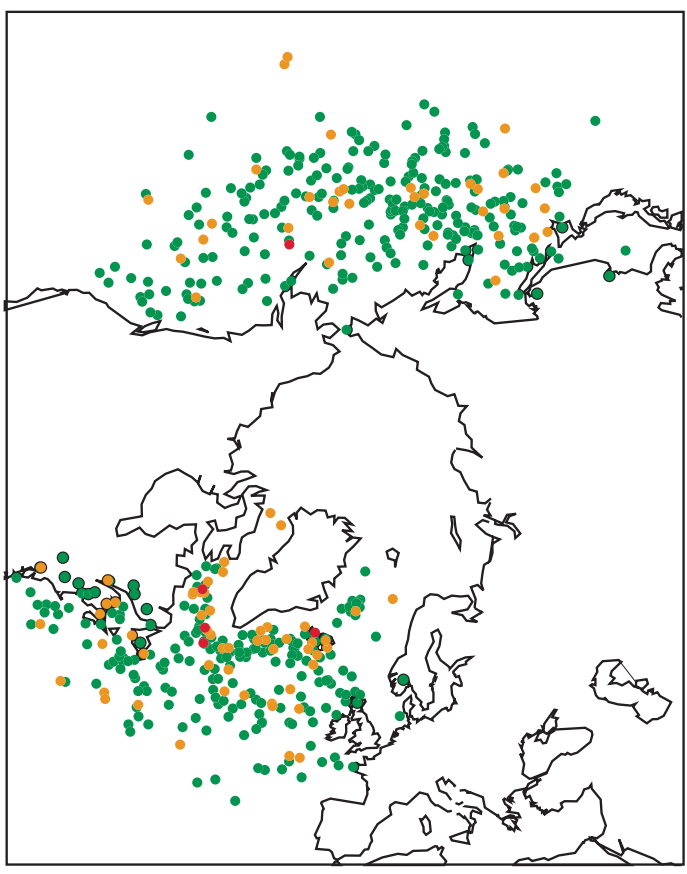

(b) $21 \mathrm{C}$

FIG. 11. Location of storms for the NH DJF, when they attain their maximum wind speed at $925 \mathrm{hPa}$ for all storms where the maximum wind speed exceeds $45 \mathrm{~m} \mathrm{~s}^{-1}$ for (a) $20 \mathrm{C}$ and (b) $21 \mathrm{C}$.

amounts to almost 3 times this amount. We suggest that the reason for this is due, in part, to the area averaging and also the extratropical cyclones, because of the dominant large-scale geostrophic processes, are much less efficient at extracting water vapor from the environment than small-scale convective processes, which are more capable of doing this.

In a similar way to the maximum wind speed, we have explored extreme precipitation both for the individual cyclones and for all individual 6-hourly grid points. Figure 13 shows the distributions of the maximum, hourly (averaged over $6 \mathrm{~h}$ ), area-averaged precipitation for both hemispheres and for all seasons. There is a clear increase in the numbers of the extreme precipitating systems in $21 \mathrm{C}$ as is most apparent in the insets for each season in Fig. 13. The relative change is broadly similar for both hemispheres and for all seasons. We have also produced distributions of the cumulative precipitation along the cyclone tracks (not shown), which show a similar behavior to the maximum precipitation with higher extreme values for $21 \mathrm{C}$ than $20 \mathrm{C}$ and the same relative differences for both hemispheres and all seasons.

Figures 14a,b show the geographical distribution of changes between $21 \mathrm{C}$ and $20 \mathrm{C}$ for the average precipitation in the $\mathrm{NH}$ for summer and winter. During winter there is an increase in precipitation north of $\sim 45^{\circ} \mathrm{N}$ with the highest increase along the storm tracks and in the Arctic. At lower latitudes there is reduced precipitation. During summer the areas of reduced precipitation further increase, particularly so for Eurasia, following the weakening of the Atlantic storm track during summer. Changes in extreme precipitation for the $\mathrm{NH}$ winter and summer (Figs. 14c,d), using the 99th percentile as a measure, have similar distributions to the mean with the largest increase along the storm tracks. It is interesting to note that the change in hourly precipitation at the 99th percentile is an order of magnitude larger than the change in the mean. Finally, in Table 4 we have summarized the result in precipitation changes for different extratropical regions and for different percentiles and contrast them to the mean as well as the absolute maximum precipitation. There are marked differences between different areas. It is interesting to note that the increase in precipitation is larger for the NH for both summer and winter than the $\mathrm{SH}$ and for all the measures of extreme precipitation. For the smaller regions of the $\mathrm{NH}$ we note the marked reduction in mean precipitation in southern Europe, which is almost halved during summer and reduced by some $20 \%$ in winter. However, in spite of that there is an increase in the absolute maximum, showing there exist some rare occasions when the extreme precipitation will be higher irrespective of the overall reduction in total precipitation. 


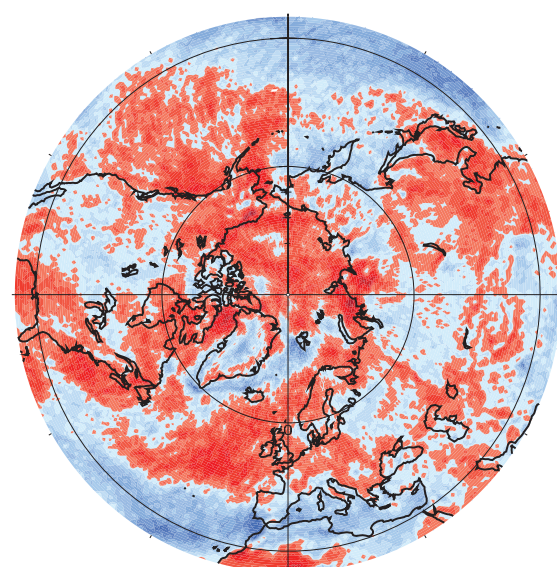

(a) $\mathrm{NH}, \mathrm{DJF}$

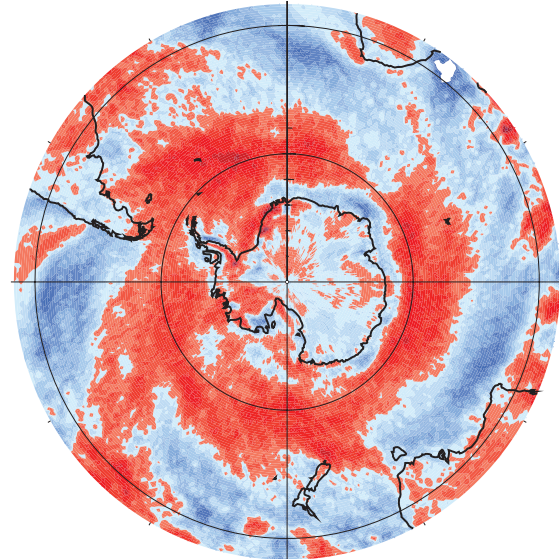

(c) SH, DJF

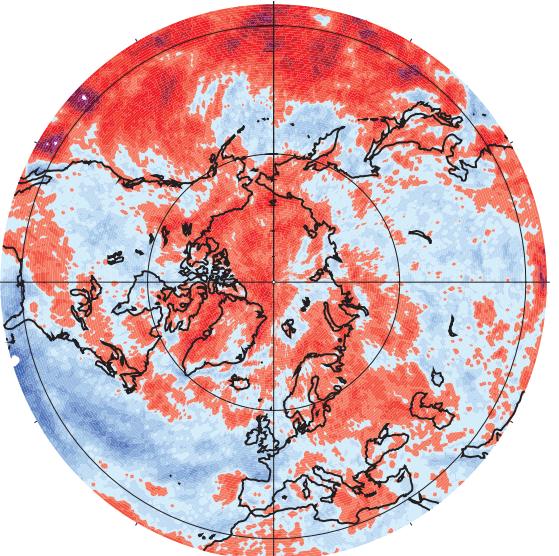

(b) $\mathrm{NH}, \mathrm{JJA}$

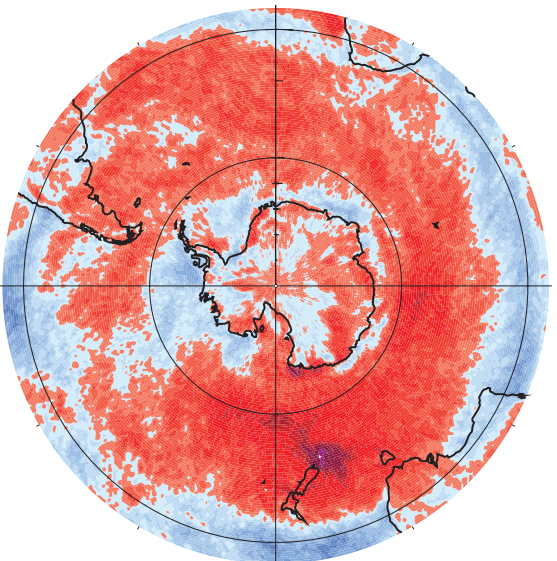

(d) $\mathrm{SH}, \mathrm{JJA}$

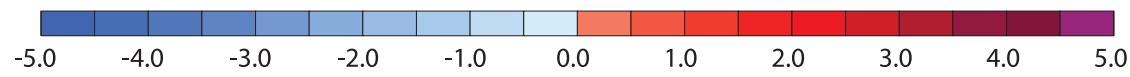

FIG. 12. Differences between $21 \mathrm{C}$ and $20 \mathrm{C}$ of the 99.5 percentiles of the $925-\mathrm{hPa}$ winds for (a) the NH DJF, (b) the NH JJA, (c) the SH DJF, and (d) the SH JJA. Units are $\mathrm{m} \mathrm{s}^{-1}$.

\section{Summary of results and discussion}

\section{a. General}

We have compared the cyclones identified in the T213 integration with those from an integration at lower horizontal resolution (T63). If we identify cyclones at a common T42 resolution, the number of cyclones as a function of maximum intensity (T42) is practically identical and has no substantial change in the distribution. Differences are within the natural variability of $30-\mathrm{yr}$ samples (Bengtsson et al. 2006). This suggests that the T63 resolution is capable of reproducing extratropical cyclone distributions but lacks only in the ability to produce more realistic extremes of wind and precipitation, which is apparent when intensities at full resolution are studied.

The model results agree well with ERA-40 except that the model results have stronger winds and larger precipitation. Preliminary assessment of the new Interim reanalyses shows values of these parameters are closer to the model. We have also compared the composite life cycles and 3D structure of extreme storms in the model and ERA-40 and found in general very good agreement, though the model produces somewhat more intense storms. The weaker winds and precipitation in the ERA-40 in part can be attributed to lower resolution, the impact of the data assimilation and deficiencies in the way such quantities as precipitation are determined.

The model winds have also been compared with observational data from the North Sea as described by Weisse et al. (2005). The result agrees well with the observations from Ekofisk and the other stations of the North Sea as well as with the results of Weisse et al. (2005). Incidentally, the results from the North Sea from the $20 \mathrm{C}$ are practically identical to those of the $21 \mathrm{C}$. 


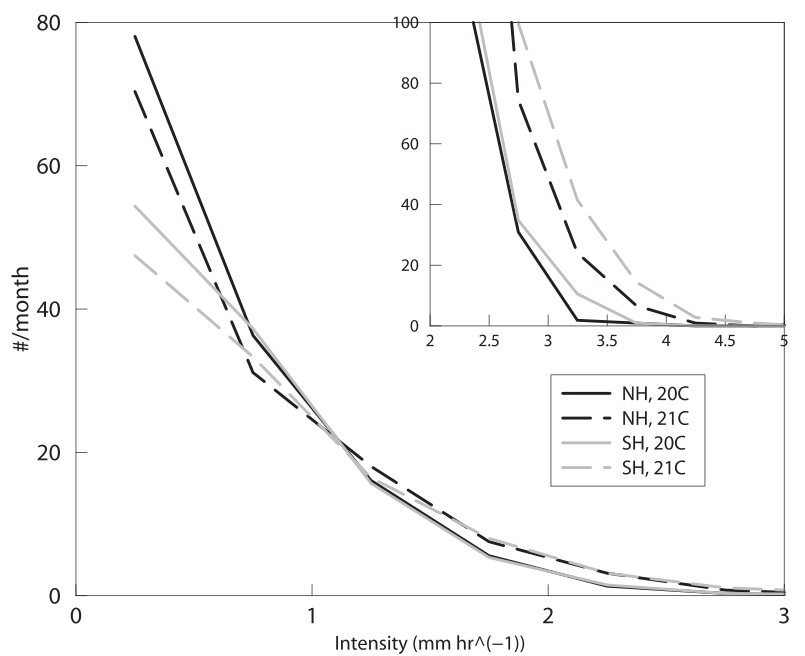

(a) DJF

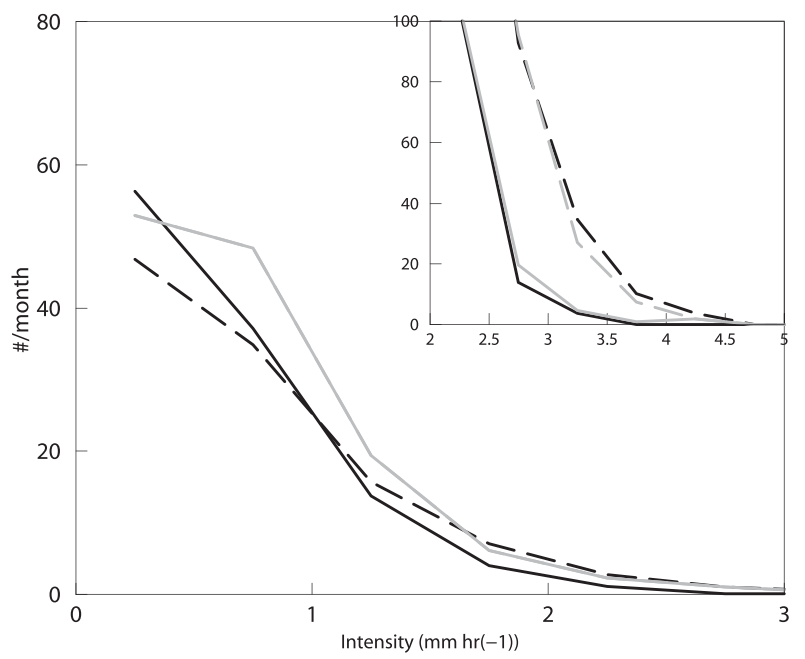

(c) JJA

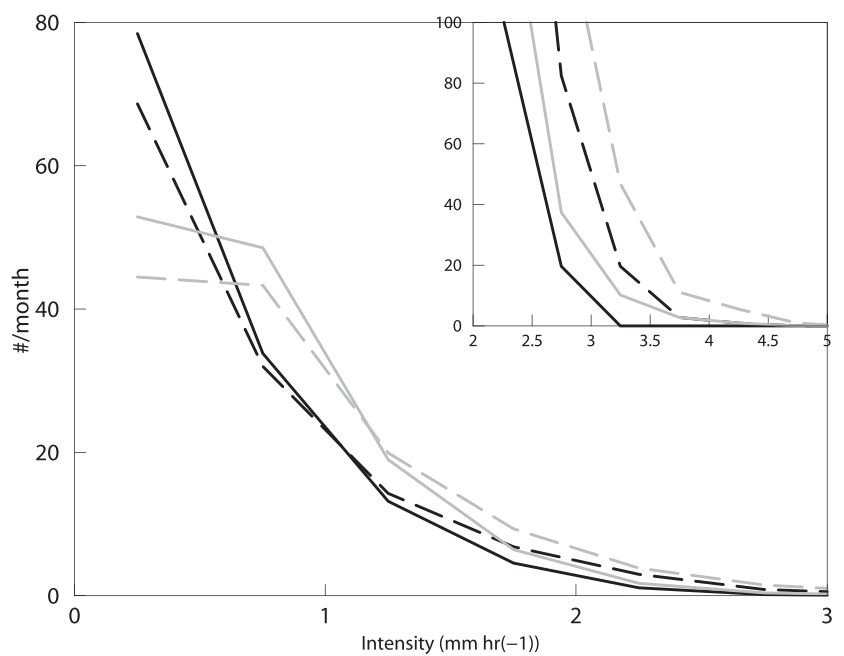

(b) MAM

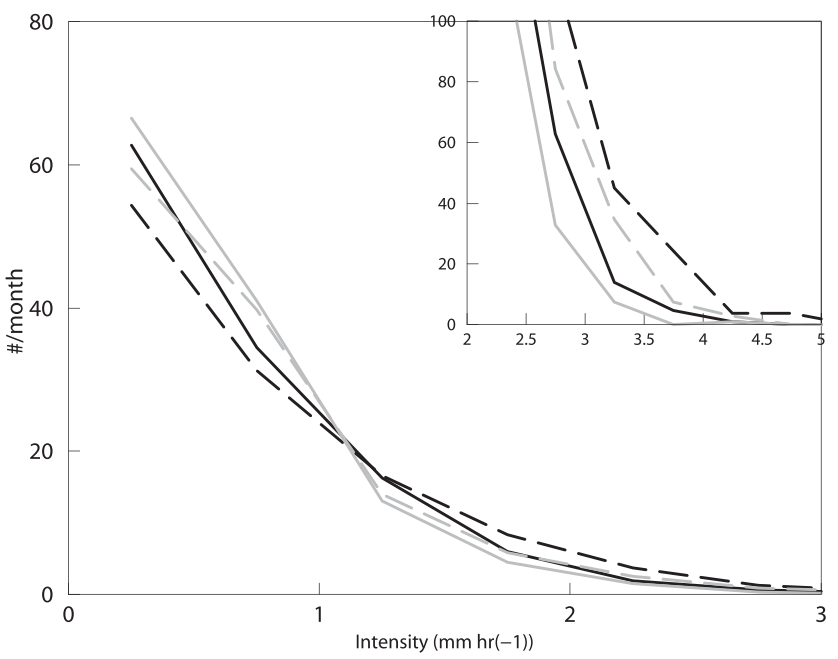

(d) SON

FIG. 13. Distributions of the maximum of the storm-centered area-averaged precipitation $\left(\mathrm{mm} \mathrm{h}^{-1}\right)$ for $20 \mathrm{C}$ and $21 \mathrm{C}$ and for NH and SH: (a) DJF, (b) MAM, (c) JJA, and (d) SON. Bin widths are $0.5 \mathrm{~mm} \mathrm{~h}^{-1}$. Insets show the tails of the distributions scaled to $90 \mathrm{months}$ (30 DJFs).

The typical evolution of intense extratropical cyclones in $20 \mathrm{C}$ and $21 \mathrm{C}$ is rather similar, as can be seen from Fig. 9a. The precipitation intensity is higher in $21 \mathrm{C}$ and the depth of the cyclones slightly deeper if we choose the storms based on the T42 $\xi_{850}$ intensities. The maximum wind speed, on the other hand, is somewhat weaker in $21 \mathrm{C}$. We have also examined the cyclones with the strongest precipitation in 20C and 21C (Fig. $9 \mathrm{~b}$ ); this shows a larger increase in precipitation between $20 \mathrm{C}$ and $21 \mathrm{C}$ but a marked reduction in intensity in terms of winds, vorticity, and pressure. Consequently, all indications are that the feedback from higher precipitation toward more intense synoptic-scale extratropical cyclones is small.

\section{b. Winds}

The evolution of the maximum wind of the most intense extratropical storms undergoes a characteristic evolution. At the time of maximum intensification the strongest winds occur in the open warm sector to the right and slightly forward of the center (Fig. 5a). At the time of maximum precipitation (Fig. $5 \mathrm{c}$ ), which occurs on average $\sim 15 \mathrm{~h}$ later, the wind speed has increased and the maximum wind has moved some $45^{\circ}$ anticlockwise. Finally, at the time of maximum intensity (Fig. 5e), occurring some $15 \mathrm{~h}$ later, the strongest winds are found in the subsiding region behind the storm. A very similar picture occurs for $21 \mathrm{C}$ (not shown); 


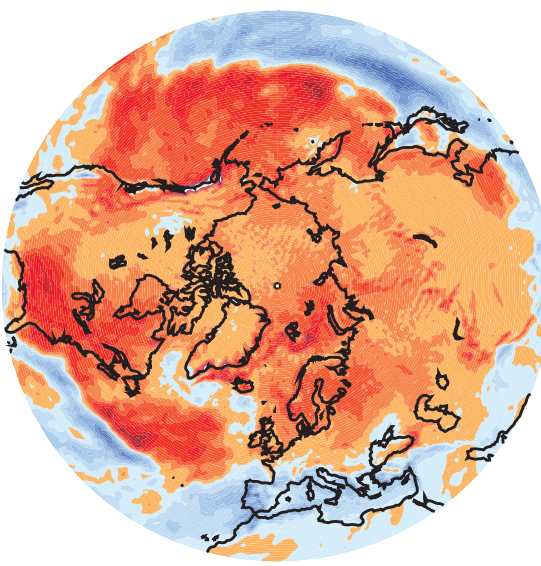

(a) AVG, DJF

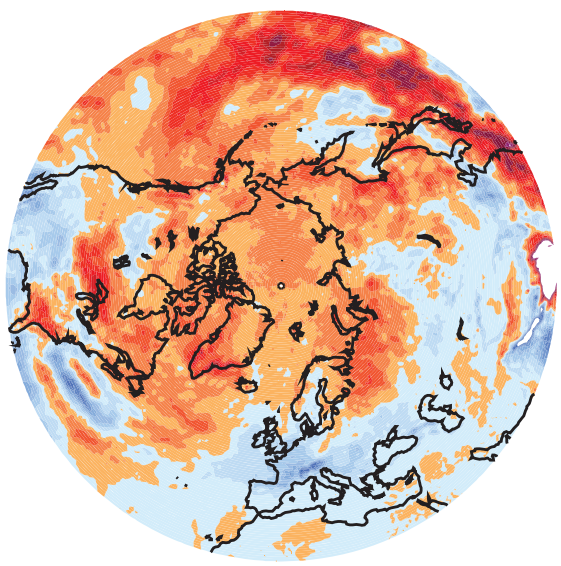

(b) AVG, JJA

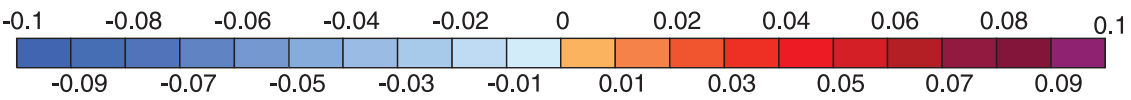

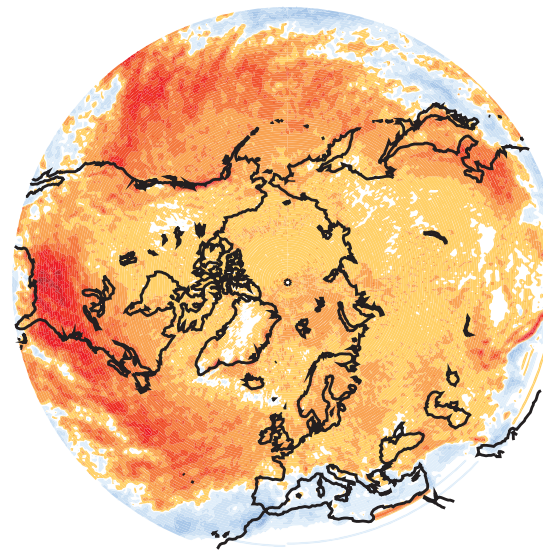

(c) $99 \%, D J F$

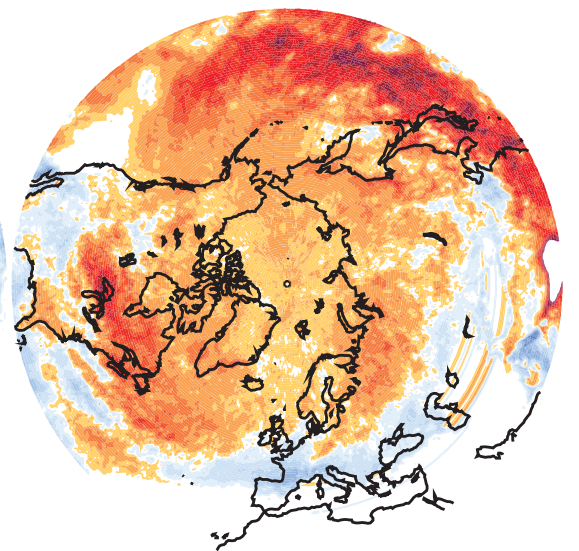

(d) $99 \% \mathrm{JJA}$

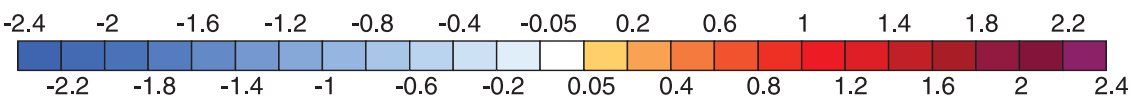

FIG. 14. Precipitation differences $\left(\mathrm{mm} \mathrm{h}^{-1}\right)$ for the NH (a) DJF time mean, (b) JJA time mean, (c) DJF 99 percentile, and (d) JJA 99 percentile.

maximum wind speed is practically identical and occurs at the same time and place relative to the storm center as for $20 \mathrm{C}$.

In the $\mathrm{NH}$ the most interesting changes occur in the Atlantic region. As cyclones move toward the southern and eastern coast of Greenland the strongest winds are found around the coasts and between Greenland and Iceland. These are regions that are known for exceptionally strong winds during the winter (Moore and Renfrew 2005). There is a tendency to a slight weakening in this area in 21C. The reason for this is not easy to understand but it maybe related to a greater preference for the storm tracks to be orientated toward the
British Isles and Scandinavia and a corresponding weakening both to the north and to the south. As discussed in Bengtsson et al. (2006), we suggest that this may be related to an enhanced SST gradient between $40^{\circ}$ and $50^{\circ} \mathrm{N}$ in the central Atlantic with associated increase in baroclinicity.

We also compared the wind speed with the model with lower resolution. While the extreme wind speed is lower in T63 this is most obvious in coastal regions where the low-resolution model is unable to reproduce the marked maximums that occur in nearby coastal regions such as along the coast of Greenland and along the Norwegian coast. 
TABLE 4. Summary of percentage changes in precipitation between $21 \mathrm{C}$ and 20C for DJF and JJA for the area averages over the regions NH $\left(25^{\circ}, 90^{\circ} \mathrm{N}\right)$; $\mathrm{SH}\left(25^{\circ}, 90^{\circ} \mathrm{S}\right)$; North America $\left(25^{\circ}, 70^{\circ} \mathrm{N}\right),\left(160^{\circ}, 65^{\circ} \mathrm{W}\right)$; North Atlantic $\left(25^{\circ}, 70^{\circ} \mathrm{N}\right),\left(80^{\circ} \mathrm{W}, 0^{\circ}\right)$; North Pacific $\left(25^{\circ}, 70^{\circ} \mathrm{N}\right),\left(120^{\circ} \mathrm{E}, 120^{\circ} \mathrm{W}\right)$; northern Europe $\left(47.5^{\circ}, 70.0^{\circ} \mathrm{N}\right),\left(10^{\circ} \mathrm{W}, 40^{\circ} \mathrm{E}\right)$; and southern Europe $\left(30.0^{\circ}, 47.5^{\circ} \mathrm{N}\right),\left(10^{\circ} \mathrm{W}, 40^{\circ} \mathrm{E}\right)$, for the time mean, maximum, and 99th and 99.9th percentile.

\begin{tabular}{|c|c|c|c|c|c|c|c|c|}
\hline & & $\mathrm{NH}$ & $\mathrm{SH}$ & $\begin{array}{c}\text { North } \\
\text { America }\end{array}$ & $\begin{array}{c}\text { North } \\
\text { Atlantic }\end{array}$ & $\begin{array}{l}\text { North } \\
\text { Pacific }\end{array}$ & $\begin{array}{l}\text { Northern } \\
\text { Europe }\end{array}$ & $\begin{array}{c}\text { Southern } \\
\text { Europe }\end{array}$ \\
\hline \multirow[t]{2}{*}{ Mean } & DJF & 8.0 & 3.4 & 14.4 & 4.0 & 5.4 & 15.4 & -19.9 \\
\hline & JJA & 8.0 & 2.2 & 6.8 & 1.9 & 15.9 & -3.5 & -47.1 \\
\hline \multirow[t]{2}{*}{$99 \%$} & DJF & 15.8 & 9.2 & 21.4 & 13.9 & 13.5 & 19.4 & -6.0 \\
\hline & JJA & 17.9 & 7.8 & 15.5 & 11.1 & 28.3 & 6.6 & -42.3 \\
\hline \multirow[t]{2}{*}{$99.9 \%$} & DJF & 23.5 & 20.9 & 30.7 & 23.3 & 21.6 & 20.1 & 4.4 \\
\hline & JJA & 30.1 & 14.0 & 30.8 & 20.0 & 42.3 & 20.2 & -24.8 \\
\hline \multirow[t]{2}{*}{ Max } & DJF & 29.4 & 25.4 & 36.3 & 30.2 & 28.8 & 20.3 & 12.6 \\
\hline & JJA & 37.1 & 18.7 & 37.6 & 29.9 & 45.9 & 32.4 & 4.1 \\
\hline
\end{tabular}

\section{c. Precipitation}

As discussed in Bengtsson et al. (2007) the ECHAM5 model is typical of other general circulation models (GCM) in increasing water vapor more rapidly than precipitation. We note that precipitation will change for a number of reasons. First, there is a general increase in global precipitation amounting to $\sim 6.2 \%$. Second, there is an overall change in the distribution of the precipitation with a larger percentage increase along the storm tracks and at higher latitudes in general. At the same time there is a marked reduction in the subtropics stretching further poleward during the summer season. This change follows broadly the changes in the hydrological cycle as discussed by Held and Soden (2006). Third, there is a marked change in the statistical distribution of precipitation, with proportionally higher precipitation at high intensity (Semenov and Bengtsson 2002) giving rise to changes in precipitation of some $30 \%$ at the highest percentiles. The combined result of these three effects implies considerable changes in extreme local precipitation, which in some areas may amount to increases of $40 \%-50 \%$.

We suggest that increases in extreme precipitation in regions where there is either an increase or a decrease in the mean will constitute a more severe problem for society than the possible risk of higher wind speeds in some areas.

Needless to say these results are model dependent and other models are likely to provide either somewhat higher or somewhat lower global precipitation. However, the general result that the increase in annual average precipitation is much lower than the increase in column water vapor is common for all models used in the IPCC AR4 (Held and Soden 2006) as is the response to enhance the regional extremes in precipitation. We also believe that the change in the skewness of the distribution of precipitation over a time interval will lead to more extreme precipitation as discussed in Semenov and Bengtsson (2002).

\section{Concluding remarks}

Extratropical cyclones have been studied in great detail using data from a T213 version of the ECHAM5 atmosphere only model forced with SST data from a coupled model at T63 resolution. We have explored the properties and structure of the cyclones and contrasted the T213 results with those from the T63 integration, modern reanalyses, and other studies. Comparison with ERA-40 and observations suggests that the ECHAM5 model at the T213 resolution simulates extratropical cyclones with great realism. This provides us with confidence in using the model to explore likely changes in extratropical cyclones and extremes in a warmer climate.

However, studies of this kind should be critically assessed in view of the fact that conclusions are based on a single model so that important questions might still be usefully considered.

\section{a. Can we have sufficient confidence in one particular climate model?}

The overall response to a warmer climate is a marked increase in column water vapor, following the ClausiusClapeyron relation in common with other GCMs. Similarly, the much slower increase in total precipitation is also common with other GCMs (Held and Soden 2006). However, also in agreement with other studies, extreme precipitation increases more rapidly than the mean precipitation (Semenov and Bengtsson 2002). This is physically credible since convectively driven weather systems are expected to more effectively use the higher level of water vapor. 
We believe we can have confidence in the change in maximum wind speed. To predict maximum wind speed in a local environment exposed to coastal and sharp orographic obstacles is not feasible with a model of the kind used here, but the model should be capable of providing reliable indicators for such predictions. We see no reason why the relation between a model predictor and a local predictand will change in a warmer climate; consequently the local extremes are not likely to change either.

The general poleward shift in the storm tracks is seen in several other studies (as discussed in the introduction); however, in a recent paper by Son et al. (2008) it is suggested that the recovery of stratospheric ozone will mitigate the poleward shift seen in the SH. The model simulations used here do include the ozone recovery from the stratospheric minimum in 1998 back to 1970 levels by 2100 , though the ozone distributions are specified and not computed via an interactive chemistry model. Thus the effect of this on the stratospheric circulation around Antarctica and its impact on the tropospheric jets reported by Son et al. (2008) is likely included, though we have not checked directly.

\section{b. Is the integration sufficiently long?}

The integrations used for this study cover two 32-yr periods. This is likely to be too short for a regional assessment of extreme conditions in extratropical cyclones (Weisse et al. 2005). However, based on the assessment of three different 30-yr integrations with the same model at lower resolution (Bengtsson et al. 2006), the overall hemispheric statistics should be robust. Reliable regional results will require longer integrations on a time scale of a century or the use of ensembles.

\section{c. Are the resolution and the physical parameterizations adequate?}

Here we are on less safe ground and it could well be the case that future ultrahigh-resolution simulations using nonhydrostatic equations will give different results. However, extratropical cyclones are well described by the quasigeostrophic equations, so we do not expect that the extratropical cyclones will be very different in a nonhydrostatic model. Also, short- and medium-range predictions with similar models are accurate with forecast errors more often related to errors in the initial state. In selected areas, where extreme wind statistics are available, the results agree with observations as well as with limited-area models. Extreme precipitation on the other hand, is likely to be even more pronounced in models with higher resolution than we have investigated here. Additional studies to clarify this will be needed. However, our view is that an accurate resolution of the synoptic-scale flow will provide more robust predictors for local extreme precipitation.

\section{d. How confident are we that the feedback from any increase of latent heat is insignificant in generating stronger winds?}

The fact that observations and theoretical considerations show that extratropical cyclones are most intense during the cold season and in situations with strong temperature gradients, and associated upper-air winds suggest that these conditions are the main drivers of extreme extratropical cyclones. In contrast to tropical cyclones where the release of latent heat is quasi-symmetrically organized around the cyclone, the extratropical cyclones are different in this respect. Moreover, the evolution of an extratropical cyclone is characterized by a rapid transient process with a fast buildup of frontal precipitation and an equally fast collapse of organized precipitation as the cyclone occludes and weakens.

To better explore the influence of latent heat release we identified the 100 most intense cyclones based upon precipitation intensity instead of vorticity maximum (Fig. 9b). These cyclones have weaker maximum winds than those chosen using the T42 vorticity maxima but the interesting result is that there is no increase in extreme winds but rather a decrease in $21 \mathrm{C}$. This further supports our view that the increase in latent heat release has only a minor direct influence on any likely intensification of extratropical cyclones.

Finally, there are reports of intense small-scale extratropical cyclones and polar lows, which have features more in common with tropical cyclones, where an enhancement by latent heat cannot be excluded. We intend to investigate this in a future study.

Acknowledgments. The work was partly supported by the EU FP6 project, ENSEMBLES (GOCE-CT-2003505539). The simulations were performed at HLRN (Norddeutscher Verbund für Hoch und Höchstleistungsrechnen). The Max Planck Institute provided ECHAM5 and additional computing resources. The authors are grateful for technical and scientific support provided by Luis Kornblueh, Monica Esch, and Erich Roeckner. The authors are also grateful to Ralf Weisse of the GKSS, Institute for Coastal Research, Germany, and Magnar Reistad from the Norwegian Meteorological Institute for providing the Ekofisk data. The authors also thank ECMWF for their provision of the ERA-40 and Interim reanalysis data. 


\section{REFERENCES}

Allan, R. P., and B. J. Soden, 2007: Large discrepancy between observed and simulated precipitation trends in the ascending and descending branches of the tropical circulation. Geophys. Res. Lett., 34, L18705, doi:10.1029/2007GL031460.

Bengtsson, L., K. I. Hodges, and S. Hagemann, 2004: Sensitivity of the ERA40 reanalysis to the observing system: Determination of the global atmospheric circulation from reduced observations. Tellus, 56A, 456-471.

,$--\ldots$, and E. Roeckner, 2006: Storm tracks and climate change. J. Climate, 19, 3518-3543.

,-- M. Esch, N. Keenlyside, L. Kornblueh, J.-J. Luo, and T. Yamagata, 2007: How may tropical cyclones change in a warmer climate? Tellus, 59A, 539-561.

Björck, S., and L. B. Clemmensen, 2004: Aeolian sediment in raised bog deposits, Halland, SW Sweden: A new proxy record of Holocene winter storminess variation in southern Scandinavia? Holocene, 14, 677-688.

Blender, R., and M. Schubert, 2000: Cyclone tracking in different spatial and temporal resolutions. Mon. Wea. Rev., 128, 377-384.

Bromwich, D. H., R. L. Fogt, K. I. Hodges, and J. E. Walsh, 2007: A tropospheric assessment of the ERA-40, NCEP, and JRA25 global reanalyses in the polar regions. J. Geophys. Res., 112, D10111, doi:10.1029/2006JD007859.

Cahn, A., Jr., 1945: An investigation of the free oscillations of a simple current system. J. Meteor., 2, 113-119.

Charney, J. G., 1959: On the theory of the general circulation of the atmosphere. The Atmosphere and the Sea in Motion: Scientific Contributions to the Rossby Memorial Volume, B. Bolin, Ed., Rockefeller Institute Press, 178-193.

Fischer-Bruns, I., H. von Storch, J. F. Gonzálaz-Rouco, and E. Zorita, 2005: Modelling the variability of midlatitude storm activity on decadal to century time scales. Climate Dyn., 25, 461-476.

Held, I. M., and B. J. Soden, 2006: Robust responses of the hydrological cycle to global warming. J. Climate, 19, 5686-5699.

Hodges, K. I., B. J. Hoskins, J. Boyle, and C. Thorncroft, 2003: A comparison of recent reanalysis datasets using objective feature tracking: Storm tracks and tropical easterly waves. Mon. Wea. Rev., 131, 2012-2037; Corrigendum, 132, 1325-1327.

Hoskins, B. J., and K. I. Hodges, 2002: New perspectives on the Northern Hemisphere winter storm tracks. J. Atmos. Sci., 59, 1041-1061.

Inatsu, M., H. Mukougawa, and S.-P. Xie, 2003: Atmospheric response to zonal variations in midlatitude SST: Transient and stationary eddies and their feedback. J. Climate, 16, 3314-3329.

Jung, T., S. K. Gulev, I. Rudeva, and V. Soloviov, 2006: Sensitivity of extratropical cyclone characteristics to horizontal resolution in the ECMWF model. Quart. J. Roy. Meteor. Soc., 132, 1839-1857.

Karl, T. R., and R. W. Knight, 1998: Secular trends of precipitation amount, frequency, and intensity in the United States. Bull. Amer. Meteor. Soc., 79, 231-241.

— , G. A. Meehl, C. D. Miller, S. J. Hassol, A. M. Waple, and W. L. Murray, Eds., 2008: Weather and climate extremes in a changing climate. Regions of focus: North America, Hawaii, Caribbean, and U.S. Pacific Islands. U.S. Climate Change Science Program Synthesis and Assessment Product 3.3, 180 pp.

Lambert, S. J., and J. C. Fyfe, 2006: Changes in winter cyclone frequencies and strengths simulated in enhanced greenhouse warming experiments: Results from the models participating in the IPCC diagnostic exercise. Climate Dyn., 26, 713-728.
Leckebusch, G. C., and U. Ulbrich, 2004: On the relationship between cyclones and extreme windstorm events over Europe under climate change. Global Planet. Change, 44, 181-193.

Löptien, U., O. Zolina, S. Gulev, M. Latif, and V. Soloviov, 2008: Cyclone life cycle characteristics over the Northern Hemisphere in coupled GCMs. Climate Dyn., 31, 507-532.

Meehl, G. A., and Coauthors, 2007a: Global climate projections. Climate Change 2007: The Physical Science Basis, S. Solomon et al., Eds., Cambridge University Press, 747-845.

_ C. Covey, T. Delworth, M. Latif, B. McAvaney, J. F. B. Mitchell, R. J. Stouffer, and K. E. Taylor, 2007b: The WCRP CMIP3 multimodel dataset: A new era in climate change research. Bull. Amer. Meteor. Soc., 88, 1383-1394.

Moore, G. W. K., and I. A. Renfrew, 2005: Tip jets and barrier winds: A QuikSCAT climatology of high wind speed events around Greenland. J. Climate, 18, 3713-3725.

Nakicenovic, N., and R. Swart, Eds., 2000: Special Report on Emissions Scenarios. Cambridge University Press, 599 pp.

Ogura, Y., 1957: Wave solutions of the vorticity equation for the 21/2-dimensional model. J. Meteor., 14, 60-64.

Oouchi, K., J. Yoshimura, H. Yoshimura, R. Mizuta, S. Kusunoki, and A. Noda, 2006: Tropical cyclone climatology in a globalwarming climate as simulated in a $20 \mathrm{~km}$-mesh global atmospheric model: Frequency and wind intensity analysis. $J$. Meteor. Soc. Japan, 84, 259-276.

Orlanski, I., and J. J. Katzfey, 1991: The life cycle of a cyclone wave in the Southern Hemisphere. Part I: Eddy energy budget. J. Atmos. Sci., 48, 1972-1998.

Pierrehumbert, R. T., H. Brogniez, and R. Roca, 2007: On the relative humidity of the atmosphere. The Global Circulation of the Atmosphere, T. Schneider and A. H. Sobel, Eds., Princeton University Press, 143-185.

Raible, C. C., M. Yoshimori, T. F. Stocker, and C. Casty, 2007: Extreme midlatitude cyclones and their implications for precipitation and wind speed extremes in simulations of the Maunder Minimum versus present day conditions. Climate Dyn., 28, 409-423.

Roeckner, E., and Coauthors, 2003: The atmospheric general circulation model ECHAM 5. Part I: Model description. Max Planck Institute for Meteorology Rep. 349, 140 pp.

— , G. P. Brasseur, M. Giorgetta, D. Jacob, J. Jungclaus, C. Reick, and J. Sillman, 2006: Climate projections for the 21st century. Max Planck Institute for Meteorology Internal Rep., 32 pp. [Available online at http://www.mpimet.mpg.de/ fileadmin/grafik/presse/ClimateProjections2006.pdf.]

Sanders, F., and J. R. Gyakum, 1980: Synoptic-dynamic climatology of the "bomb." Mon. Wea. Rev., 108, 1589-1606.

Semenov, V. A., and L. Bengtsson, 2002: Secular trends in daily precipitation characteristics: Greenhouse gas simulation with a coupled AOGCM. Climate Dyn., 19, 123-140.

Solomon, S., D. Qin, M. Manning, M. Marquis, K. Averyt, M. M. B. Tignor, H. L. Miller Jr., and Z. Chen, Eds., 2007: Climate Change 2007: The Physical Science Basis. Cambridge University Press, 996 pp.

Son, S.-W., and Coauthors, 2008: The impact of stratospheric ozone recovery on the Southern Hemisphere westerly jet. Science, 320, 1486-1489.

Temperton, C., 1973: Some experiments in dynamical initialization for a simple primitive equation model. Quart. J. Roy. Meteor. Soc., 99, 303-319.

Teng, H., W. M. Washington, and G. A. Meehl, 2008: Interannual variations and future change of wintertime extratropical cyclone activity over North America in CCSM3. Climate Dyn., 30, 673-686. 
Trenberth, K. E., and Coauthors, 2007: Observations: Surface and atmospheric climate change. Climate Change 2007: The Physical Science Basis, S. Solomon et al., Eds., Cambridge University Press, 235-336.

Tsukernik, M., D. N. Kindig, and M. C. Serreze, 2007: Characteristics of winter cyclone activity in the northern North Atlantic: Insights from observations and regional modeling. $J$. Geophys. Res., 112, D03101, doi:10.1029/2006JD007184.

Ulbrich, U., J. G. Pinto, H. Kupfer, G. C. Leckebusch, T. Spangehl, and M. Reyers, 2008: Changing Northern Hemisphere storm tracks in an ensemble of IPCC climate change simulations. $J$. Climate, 21, 1669-1679.

, G. C. Leckebusch, and J. G. Pinto, 2009: Extra-tropical cyclones in the present and future climate: A review. Theor Appl. Climatol., 96, 117-131.
Uppala, S. M., and Coauthors, 2005: The ERA-40 Re-Analysis. Quart. J. Roy. Meteor. Soc., 131, 2961-3012.

Wang, X., V. R. Swail, and F. Zwiers, 2005: Climatology and changes of extratropical cyclone activity: Comparison of ERA-40 with NCEP-NCAR reanalysis for 1958-2001. J. Climate, 19, 3145-3166.

WASA Group, 1998: Changing waves and storms in the northeast Atlantic? Bull. Amer. Meteor. Soc., 79, 741-760.

Weisse, R., H. von Storch, and F. Feser, 2005: Northeast Atlantic and North Sea storminess as simulated by a regional climate model during 1958-2001 and comparison with observations. $J$. Climate, 18, 465-479.

Yin, J. H., 2005: A consistent poleward shift of the storm tracks in simulations of 21st century climate. Geophys. Res. Lett., 32, L18701, doi:10.1029/2005GL023684. 